\title{
LA PERCEPCIÓ DE LA PARLA I LA PARLA DELS INFANTS
}

\author{
Glòria Ester i Subias \\ Departament d'Educació de la Generalitat de Catalunya \\ gester@xtec.cat
}

\begin{abstract}
Resum
Els infants de 2-3 anys, encara no alfabetitzats, solen produir una parla que es considera que presenta característiques diferenciadores respecte del model adult que senten.

S'han analitzat els factors que intervenen entre percepció i producció de la parla en interacció infant-mestra en una mostra de 617 paraules, per conèixer si els processos de simplificació fonològica establerts per a aquesta edat, són la causa de les "errades", o més aviat són degudes a l'acomodació de l'infant al reproduir el model que percep.

El resultat de l'anàlisi en correlació infants-mestres ha demostrat un alt grau de coincidència en les produccions dels dos i per tant es va concloure que les errades no van ser a causa d'un desenvolupament fonològic deficient, atès que eren infants amb capacitats cognitives i comunicatives adequades, sinó a processos de simplificació fonològica que responien a les característiques pròpies de la parla espontània.
\end{abstract}

Paraules clau: Parla espontània, percepció, producció, processos de simplificació fonològica, competència comunicativa.

\begin{abstract}
Resumen
Los niños de 2-3 anys, aún no alfabetizados, suelen producir un habla que se considera que presenta características diferenciadoras respecto del modelo adulo que escuchan.
\end{abstract}

Se han analizado los factores que intervienen entre percepción y producción del habla en interacción niño-maestra en una muestra de 617 palabras, para saber si los procesos de simplificación fonológica establecidos para esta edad son la causa de sus "errores", o más bien son debidas a la acomodación del niño 1 reproducir el modelo que percibe.

El resultado del análisis en correlación niños-maestras ha demostrado un alto grado de coincidencia en las producciones de los dos y, por tanto, se concluye que los errores no han sido causados por un desarrollo fonológico deficiente, ya que se trataba de niños con capacidades cognitivas y comunicativas adecuadas a u edad, sino a procesos de simplificación fonológica que respondían a las características propias del habla espontánea.

Paraules clau: Habla espontánea, Percepción, Producción, Processos de simplificació fonològica, Competencia comunicativa. 


\begin{abstract}
Not yet literate children in the 2 to 3 age range tend to produce a speech that is considered presents differentiating characteristics in reference to the adult model they listen to.

Factors intervening in between children-teacher speech perception and production have been analyzed from a sample of 617 words, with the objective to unveil if phonological simplification processes established for this age range are the cause of the "mistakes" or on the contrary they are caused due to accommodation of the child during the reproduction of the model that they hear.

Children-teacher correlation analysis result demonstrates a high degree of matches in the production of both, because of this it was concluded that mistakes were not caused by deficient phonological development, due to the fact that children had adequate communicative and cognitive abilities, but rather to phonological simplification processes related to spontaneous speech characteristics.
\end{abstract}

Keywords: Spontaneous Speech, Perception, Production, Phonological Simplifying Processes, Communicative Competence

\title{
1. PRESENTACIÓ
}

Quan l'infant encara no està alfabetitzat els seus actes de parla es troben emmarcats en un diàleg oral amb l'adult, sovint restringit a l'àmbit familiar o al de la llar d'infants on va. Ara bé, la seva parla no la podríem situar en la categoria de llegida ni tampoc en l'espontània o lliure, tampoc encara en la dirigida, sinó en la semiespontània on els interlocutors interactuen en situacions comunicatives diverses. Un exemple d'aquestes es podria situar en l'explicació d'una història popular donant-li només uns dibuixos com a guia.

Aquest tipus de parla sol presentar una sèrie de desviacions en la pronunciació respecte de la dels adults. A tall d'exemple: [pi'Aesa] per princesa; [kenza'do] per penjador; [bet] per verd; [sa'lada fa'mi $\lambda \mathrm{a}$ ] per sagrada família, etc. A la vegada, són una mostra de la parla que és característica dels infants de poc més de 2 anys.

Aquestes diferenciacions o desviacions amb la parla dels adults poden ser degudes a diverses causes:

L'infant podria presentar un desenvolupament fonològic deficient de naturalesa articulatòria o bé auditiva. Potser les seves capacitats cognitives i comunicatives no siguin les adequades a la seva edat i nivell perquè tingui algun tipus de retard. Una altra causa podria ser que durant els seus actes de parla es trobés en una situació comunicativa que li fos adversa i no s'hi trobés còmode. Fins i tot caldria pensar en els marcs de referència, és a dir, la llengua d'ús i el nivell d'aquesta, en el cas que fossin poc o gens adequats a la seva edat.

Ara bé, en la parla espontània dels adults també es poden trobar pronúncies semblants a les dels infants, que els oients adults mediatitzats per l'escriptura no percebem com a tals, no ens n'adonem. Per exemple,

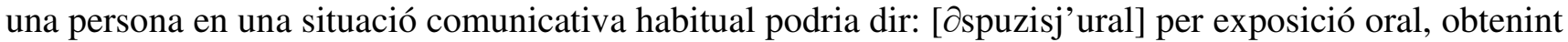
la comprensió oral dels seus oients, però de fet, no hauria pronunciat canònicament tots els sons.

Aquest va ser el nucli o interès d'aquesta investigació relacionada amb el tema de la percepció de la parla i parla dels infants, que es va estructurar en tres parts ben diferenciades: la introductòria amb un suport de coneixement científic i teòric sobre el desenvolupament fonològic dels infants de $2-3$ anys; l'elaboració PHONICA, vol. 15, p. 50-80, 2019 
de la investigació i la seva aplicació i, per últim, les conclusions sobre l'anàlisi de les causes que van intervenir en les desviacions de la parla dels infants d'aquesta edat amb capacitats adequades, quan interactuaven amb l'adult en conversa semiespontània.

La investigació es va basar en una possible relació entre les pronúncies espontànies dels adults i la percepció rebuda per part dels infants encara no alfabetitzats. L' objecte d'estudi va recaure en els elements de la situació comunicativa que van servir de punt de partida: un infant i una mestra i una conversa semiespontània entre els dos interlocutors, en interacció, ara parlava un, ara parlava l'altra. Per tal de descobrir aquesta relació, es van realitzar:

- Enregistraments d'enunciats diferenciadors dels infants en la seva parla espontània o semiespontània en el moment en què interactuaven amb la mestra, per tal de crear el corpus de paraules o enunciats diferenciadors a estudiar, tal com s'explicarà a la metodologia.

- Recerca de coneixement científic sobre el desenvolupament fonològic dels infants, per ubicar en aquest camp el tema de les desviacions o diferenciacions en la parla dels infants respecte de la parla dels adults i, a la vegada, interrelacionar-lo amb el coneixement psicopedagògic de les característiques de l'etapa de l'Educació Infantil, pròpies dels infants de 2-3 anys.

\section{INTRODUCCIÓ}

El propòsit no va ser incidir només en el procés fonològic dels infants, sinó donar una mirada diferent a les seves diverses produccions quan en situació de parla espontània rebien uns models de llengua dels quals ells havien de fer-ne la percepció prèvia a la producció.

Per aquest motiu, va ser necessari entrar en el marc del desenvolupament fonològic per conèixer-lo i veure què s'esdevé durant els dos primers anys de vida de l'infant, uns anys que estan considerats d'excepcionals pels canvis ràpids que experimenten en aprendre llengua. Durant aquest període l'infant passa de ser un principiant, quan es comunica mitjançant indicis i fa servir procediments lingüístics com, per exemple, a l'observar imatges d'una il-lustració o reaccionar a una onomatopeia i va a l'avanç progressiu en l'adquisició de sons i en el llenguatge verbal propis de l'etapa lingüística. Aproximadament entre els 12 i 36 mesos, ja esdevé un productor de la parla del seu entorn sociocultural.

Això és possible perquè l'infant és hàbil, és ràpid, discrimina sons, ve a ser protagonista del seu propi procés, també és interactiu, cooperador, cognitiu i aprèn llengua. Aquest recorregut cronològic, progressiu i complex es va farcint de múltiples matisos per ajudar-lo a establir un ordre o seqüenciació en l'adquisició fonològica i quan un infant el manifesta, entra dins del concepte de normalitat.

La primera dada que sorgeix quan s'estudia aquest camp és que, a partir de Jakobson i l'Escola de Praga, la teoria fonològica va quedar formulada i es va explicar el fenomen de l'adquisició i producció de sons per part dels infants. A partir d'aquell moment (1941), molts investigadors es van interessar en aquest tema i es va entrar en l'anàlisi dels retards i trastorns a nivell fonològic, però més aviat per establir-ne una intervenció o reeducació. Més recentment, s'ha donat una mirada diferent a aquest tema i se sol posar l’èmfasi en la interacció que es produeix entre percepció i producció.

Les diverses teories sobre el procés de desenvolupament fonològic d'aquest període d'edat, mostren aspectes de l'estudi de les capacitats dels infants i totes tenen patrons comuns. Algunes defensen que l'adquisició fonològica és automàtica; altres consideren que l'adquisició és interactiva i el paper de l'infant esdevé actiu, perquè intervé la seva cognició al fer ús d'aquestes capacitats. És des d'aquesta perspectiva 
teòrica que es van observar alguns dels fenòmens i característiques de la parla dels infants que van participar en aquesta recerca. (Mowrer,1960; Waterson, 1971; Goldsmith, 1990; Prince i Smolensky, 1993; Kenstowick, 1994; Aguilar i Serra, 2004; etc.).

En la mateixa línia I.Vila (1999), destaca l'aportació de N.Chomsky (1975), qui caracteritza el llenguatge des del punt de vista de la creativitat, com a capacitat innata humana per comprendre i reproduir enunciats, a partir del coneixement d'un nombre finit de regles LAD (Language Acquisition Device) i la de J.Bruner (1986), qui introdueix el concepte de LASS (Language Acquisition System Suport), com un dispositiu que "ajuda els aspirants a parlar-lo". Certament, els dos admeten la presència d'una naturalesa innata que permet l'accés al llenguatge, però Bruner no la circumscriu només a l'aspecte lingüístic, ni d'única competència al nadó, sinó que transcendeix a les rutines d'intercanvi social i en cooperació amb l'adult. Així que els dos interactuen comunicativament.

Fins fa poc no hi havia gaire informació sobre les primeres etapes d'adquisició fonològica, és a dir, les de balboteig i la de les primeres 50 paraules i es circumscrivia al període d'expansió del repertori fonètic o sigui des d'un any i mig fins als 6-7 anys. Més endavant, es va donar atenció al període entremig dels 4 anys. Però actualment, M.Vihman (2014) fa una anàlisi més exhaustiva, partint del naixement de l'infant fins als 2 mesos, 4 mesos, 6 mesos i l'allarga fins als 18 mesos. Per tant, hi ha hagut una implementació de períodes d'edat, presentant diferents punts de vista pel que fa a l'aprenentatge d'adquisició, que es pot agrupar a partir d'aquests criteris:

- Per classes de sons segons contrastos.

A partir d'una seqüenciació, en etapes progressives, segons contrastos de fonemes, des d'un primer contrast o model universal. Així, so agut i greu, primers contrastos entre vocals o sons oberts, més enèrgics o menys enèrgics, oclusius, fricatius, líquids... (J.M. Aceña 1996).

- Per graus de dificultat:

Les investigacions existents sobre el procés d'adquisició de sons específics per part dels infants, coincideixen en què els sons oclusius són assolits abans que els nasals; els nasals abans que els fricatius; els fricatius i africats abans que els líquids, etc. (Bosch, 1982; González 1989b; Serra 1979). Altres autors jerarquitzen l'adquisició de fonemes explosius simples fàcils, mitjanament fàcils i difícils; després fonemes implosius fàcils, diftongs decreixents i grups consonàntics.

- Per etapes d'edat:

En línies molt generals es produeix la següent seqüenciació:

Naixement: Primers sons. Etapa prelingüística en progressió fins als 4 anys.

4 anys : Discriminació de sons en paraules simples.

6-7 anys : Domini de certes síl·labes i fonemes complexos.

Fins i tot, Miras (1992), fa referència a dos aspectes interessants:

- La intel-ligibilitat de la producció sonora de l'infant. Una dada interessant és que durant el primer any de vida, el $64 \%$ de la producció sonora és intel-ligible a la mare; als 4 anys la intel-ligibilitat arriba al $99,8 \%$.

- El control articulatori de la producció sonora de l'infant. Durant el primer any de vida l'aconsegueix en un 16\%; als 2 anys en un 43\%; als 3 anys en un $71 \%$ i als 4 anys en un $87 \%$. 
Destaca en el seu treball, que el grup d'infants d'un any que hi va participar presentava tots els trets de contrast fonològic, excepte dos. Constata que l'infant d'un any té habilitats innates que, unides a la seva experiència, són suficients perquè comenci a reconèixer paraules que sent al seu voltant. Cal tenir en compte que els seus resultats els va presentar a partir d'una sèrie de controls articulatoris referits als elements fonèmics de la paraula (whitin word) i a la paraula en la seva totalitat (whole word).

El procés d'adquisició fonològica o de desenvolupament fonològic, té el punt d'arrencada en els trets distintius i en la funció que tenen en l'aprenentatge fonològic.

Els trets distintius diferencien un fonema d'un altre, formant un parell mínim. Si un d'ells és present en un fonema es marca amb un signe $+\mathrm{i}$ si no hi és amb un signe -. Això permet definir cada fonema per oposició a un altre.

A tall d'exemple, els fonemes fricatius presenten els trets distintius següents:

\begin{tabular}{|l|c|c|c|c|c|c|}
\cline { 2 - 7 } \multicolumn{1}{c|}{} & \multicolumn{6}{c|}{ FONEMES FRICATIUS } \\
\cline { 2 - 7 } \multicolumn{1}{c|}{} & $\mathrm{s}$ & $\mathrm{z}$ & $\boldsymbol{\int}$ & 3 & $\mathrm{f}$ & $\mathrm{V}$ \\
\hline sonorització & - & + & - & + & - & + \\
\hline làbio-dental & & & & & + & + \\
\hline apical & + & + & & & & \\
\hline palatal & & & + & + & &
\end{tabular}

+: presència del tret; -: absència del tret; casella buida: no funcionalitat del tret

En l'aprenentatge fonològic la funció dels trets distintius té un paper primordial i va aparellada amb els processos fonològics juntament amb les regles i estratègies de simplificació de la parla.

L'infant analitza els sons i els experimenta i va adquirint-ne els trets distintius de cadascun d'ells en la llengua que sent per establir els contrastos corresponents (J.M. Aceña, 1996). Per tant, els infants a part de la rellevància i del contrast, descobreixen una jerarquia i una generalització que apliquen de seguida.

Ferguson i Garnica (1982) afirmen que l'infant fa l'adquisició fonològica per contrastos i associa al so el significat. Schvachkin (1973), Clark (1977) i Fry (1982), manifesten que l'infant aprèn a contrastar sons només quan construeix diferència de significat.

Ara bé, cal saber com avança l'infant en el seu desenvolupament fonològic, ja que compta amb elements que ho afavoreixen.

L'infant avança molt abans de les primeres paraules. Els actuals i ràpids canvis tecnològics com l'espectroscòpia d'infrarrojos i altres sofisticades tècniques de transcripció i codificació durant l'escolta de l'àudio i visualització del video, permeten una millor comprensió del cervell infantil. També la magnetoencefalografia (MEG), que proporciona una manera de combinar la informació temporal i espacial, ha possibilitat nous mètodes per obtenir informació per a l'estudi del desenvolupament fonològic dels nadons. Ja és conegut que quan són a l'úter matern adquireixen parts importants del seu llenguatge fonològic nadiu que es va configurant de manera progressiva i precoç (Peperkamps, 2003).

Als 2-3 anys, l'infant compta a més a més amb una sensibilitat o consciència fonològica per manipular, notar, pensar els sons individuals que hi intervenen. És una capacitat metalingüistica incipient però forma part del seu procés fonològic que el va entrenant per ser hàbil a l'hora d'identificar sons o saber quina 
posició tenen en una paraula. Anys més tard, aquesta habilitat ben entrenada, l'ajudarà en el seu procés de lectoescriptura.

Simultàniament, l'infant a nivell intern té la capacitat de modificar un morfema perquè les variacions al·lofòniques, al·lomòrfiques o les restriccions fonotàctiques l'avisen de com ha de fer la pronunciació més convenient. Per tant, també compta amb una representació subjacent de cada fonema que ha adquirit.

D'aquesta manera va construint el seu propi inventari fonètic que el va ajudant en les realitzacions que ha de fer. Aleshores, quan converteix un fonema en un al-lòfon construeix paral-lelament un altre inventari: el fonèmic. Tot plegat li ve donat per les regles al·lofòniques que l'orienten no només en la descripció dels fonemes, sinó també en les posicions en què es poden trobar. Quan un infant modifica una regla adulta que sent per una altra que a ell li és millor, fa servir una regla fonològica pròpia, que pot presentar moltes variants: neutralitzar, debilitar, reforçar, etc. Les regles fonològiques l'ajuden a relacionar el nivell de representació fonològica que és abstracte o subjacent amb el de representació fonètica que és el nivell articulatori o superficial.

No es pot afirmar que això sigui un procés d'ordre universal, però al fer una comparació en moltes llengües s'arriba a la conclusió que l'infant usa unes estratègies individuals per reeixir en el seu aprenentatge. Primer, adquireix un número reduït de trets distintius, després els va contrastant i va ampliant el seu repertori. No els aprèn en sèrie sinó en context. Més endavant aprèn síl·labes i paraules que sent i utilitza. A partir d'aquí domina els fonemes o trets distintius i va acomodant les seves produccions en funció de l'adquisició i el procés que experimenta. Això ho fa a nivell intern o subjacent i tots els gestos articulatoris exactes requerits per fer-ne una producció, els sol simplificar.

Un element de naturalesa diferent que afavoreix el desenvolupament fonològic de l'infant és la seva capacitat perceptiva que fa possible la transició a l'ús del llenguatge, quan estudia el moviment de la cara i de la veu dels adults i gradualment s'hi acomoda i els reprodueix (Vihman, 2014). No hi ha dubte que, des de la perspectiva del significat, experimenta, comunica i actua; des de l'oralitat, escolta i parla.

Així, posa en joc les seves competències comunicatives envers la seva capacitat fonològica en la pronunciació: els canvis de to, d'intensitat, d'entonació i els aspectes melòdics dels enunciats, la prosòdia.

Però també té una sèrie d'elements en contra (González, 1989b):

- Capacitat limitada de memòria, que evidencia una baixa retenció.

- Capacitat limitada de representació, atès que només emmagatzema representacions simplificades.

- Destresa articulatòria limitada, ja que triga a igualar-se a l'adult. (Dale 1980b)

Al llarg de l'aprenentatge fonològic, especialment fins als 3 anys, quan ja domina els trets distintius, l'infant sol cometre errades en el seu intent d'acomodar-se a la parla de l'adult, però després van perdent importància (Ingram, 1974).

Si el desenvolupament és l'adequat aquestes acomodacions no es poden considerar errades. Ara bé, si es tracta d'un infant amb dificultats fonològiques caldrà aplicar-li un tractament dirigit a ajudar-lo. Existeixen models per analitzar errades i dificultats fonològiques que parteixen de l'habilitat cognitivomotora en els processos implicats en la producció de la parla. Mostren la naturalesa de l'errada a partir dels nivells de processament afectats. 
Actualment, es posa l'accent en els nivells de representació de les paraules, els quals estan organitzats jeràrquicament $\mathrm{i}$ no en representacions lineals de segments seqüencials. Per tant, es té en compte la prosòdia, l'estructura sil·làbica i els trets distintius.

En aquesta mateixa línia, Aguilar i Serra (2004) van anar més enllà d'analitzar el component segmental i van establir una anàlisi jeràrquica per entendre millor les limitacions dels infants. Així van eixamplar el sistema tradicional i van establir tres nivells fonològics: els més innovadors, el de la paraula sola o connectada i el de la tonicitat de les síllabes; el més tradicional, el dels segments.

Aquestes "errades", alguns autors les anomenen ajustaments, fenòmens temporals, errors en l'articulació de sons, trastorns, dificultats, canvis fonètics o fonèmics, processos substitutoris... Ve a ser com una estratègia per simplificar la parla que senten de l'adult, que m'he decantat per anomenar acomodació.

Alguns autors els classifiquen en subprocessos, segons l'infant simplifiqui la complexitat articulatòria de seqüències concretes, altres els categoritzen segons estiguin relacionats amb l'estructura sil·làbica 0 tinguin a veure amb l'assimilació d'un segment en una mateixa paraula, o substitueixin classes senceres de sons. Bosch (1983b), identifica un total de 36 processos i subprocessos de simplificació de la parla; Grunwell (1985) n'identifica 14 i Hodson i Paden (1985) 42, etc.

Quan s'ha d'analitzar la producció de sons en infants de 2-3 anys, és important tenir present l'abundant llista de simplificacions possibles que realitzen i observar aquests ajustaments, errades, trastorns o processos de simplificació fonològica que és la terminologia més freqüent. Uns procedeixen d'investigacions de més llarga tradició perquè afecten a l'anàlisi a nivell segmental, altres parteixen de perspectives d'anàlisis més actuals, a nivell de la paraula i a nivell de la síl·laba. De fet, hi ha hagut una progressió des de la fonologia generativa de Chomsky i Halle (1968), passant per la fonologia natural (Stampe, 1979), la fonologia autosegmental o mètrica (Goldsmith, 1990; Kenstowick, 1994), fins i tot l'Optimal Theory de Prince i Smolensky (1993). És a partir d'aquests models que alguns autors han estudiat el desenvolupament fonològic dels infants i han observat aquests ajustaments, errades, trastorns o processos de simplificació fonològica, classificant-los per edats i nivells, en alguns casos tenint com a objectiu una línia preventiva. De fet, segons la quantitat de simplificacions que l'infant realitzi, es pot obtenir el seu nivell de desenvolupament fonològic. A continuació, hi ha una recopilació de tots aquests processos que més endavant van servir per analitzar les produccions enregistrades per a aquesta investigació. (Quadre 1).

L'aprenentatge fonològic de l'infant el concreta, habitualment, en dos àmbits: el familiar i el de la llar d'infants, mitjançant uns estils de parla que pot ser fomentada per una història popular donant només uns dibuixos com a guia a l'informant per fer sorgir la parla semiespontània. És en aquest marc que l'infant aprèn que els actes de parla estan regits per torns de conversa, per preguntes, per demandes d'aclariment i per un sistema de regulació contínua (Luque, 1987).

Qualsevol missatge que el seu cervell generi l'haurà de materialitzar en la veu i això es veurà afectat per la seva edat, condicions psicofísiques, manera d'expressar-se, estat emocional, presència d'un soroll ambiental, un refredat... que el timbre i la prosòdia de la seva veu ho reflectirà (Nadeu, 2012). 


\begin{tabular}{|c|c|c|c|}
\hline \multicolumn{4}{|c|}{ PROCESSOS DE SIMPLIFICACIÓ FONOLÒGICA } \\
\hline \multirow{2}{*}{\multicolumn{2}{|c|}{ Nivell de LA Paraula }} & NivelL de LA Síl-LABA & NIVELL SEGMENTAL \\
\hline & & $\begin{array}{l}\text { Afecten primàriament l'estructura interna de la síl.laba } \\
\text { i secundàriament poden afectar el nivell segmental. }\end{array}$ & $\begin{array}{l}\text { Simplificació de fonemes. Prové d'una deficient } \\
\text { discriminació o articulació dels segments }\end{array}$ \\
\hline \multicolumn{2}{|r|}{$\begin{array}{l}\text { 1) CANVIS EN L'ESTRUCTURA } \\
\text { Nombre de síl-labes que es poden mantenir a l'hora de } \\
\text { produir }\end{array}$} & \multirow{2}{*}{ 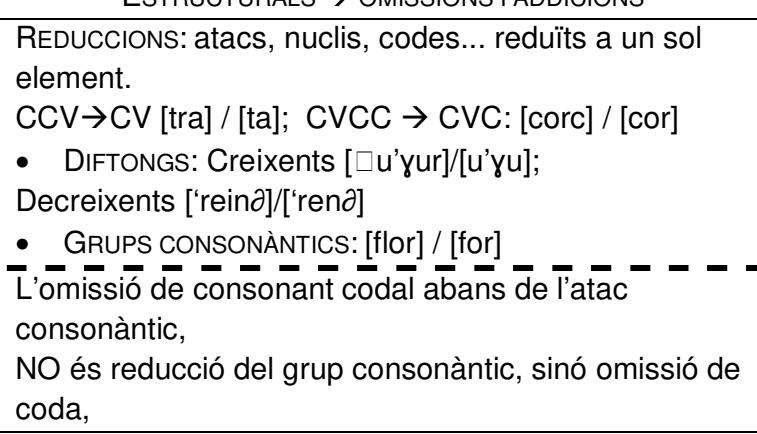 } & \multirow{6}{*}{ 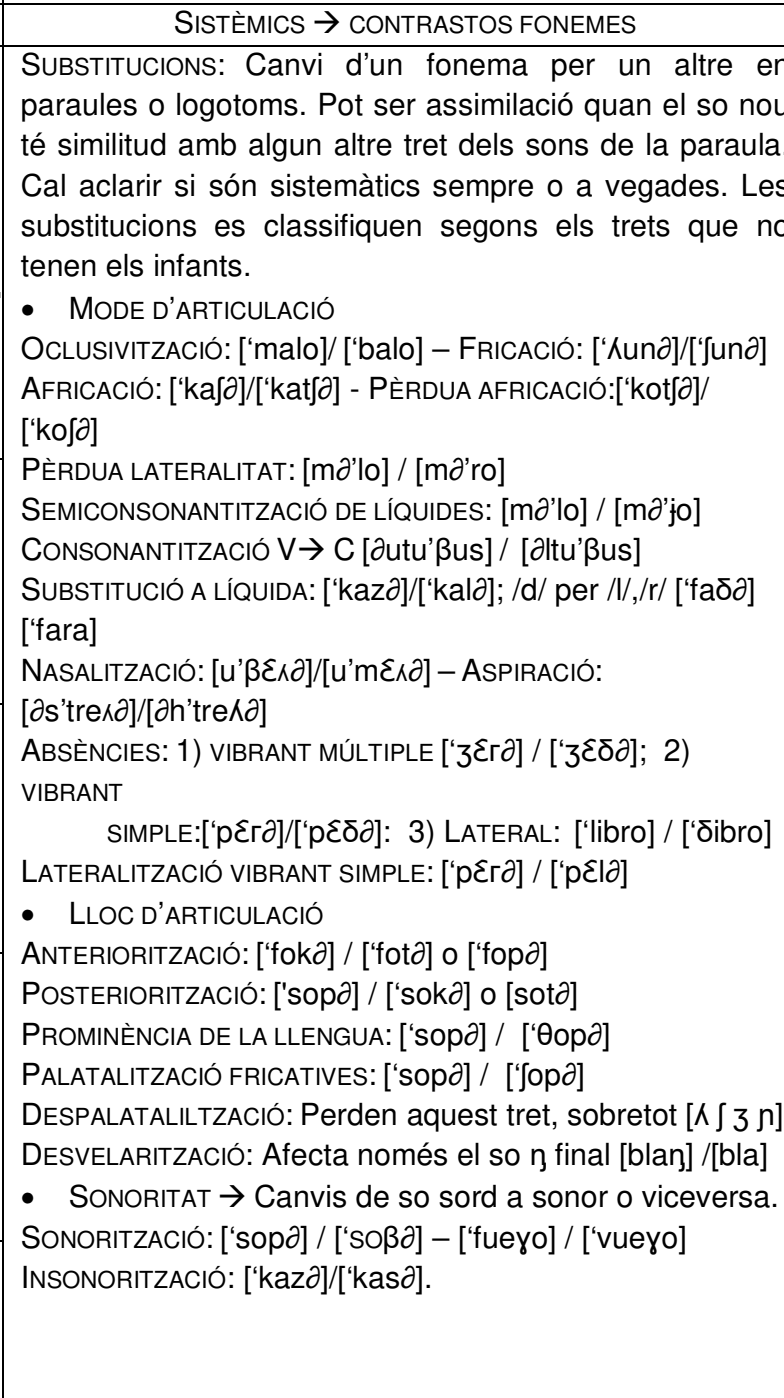 } \\
\hline & \multirow[t]{2}{*}{$\begin{array}{l}\text { OMISSIONS } \rightarrow \text { D'una síl-laba dins de la paraula } \\
\text { - TÒNIQUES (poc usual) } \\
\text { - ÀtonES } \\
\text { Síl-LABA INICIAL (freqüent) } \\
\text { Síl-LABA FINAL (molt poc freqüent) } \\
\text { Síl-LABA MITJANA (poc freqüent) }\end{array}$} & & \\
\hline & & 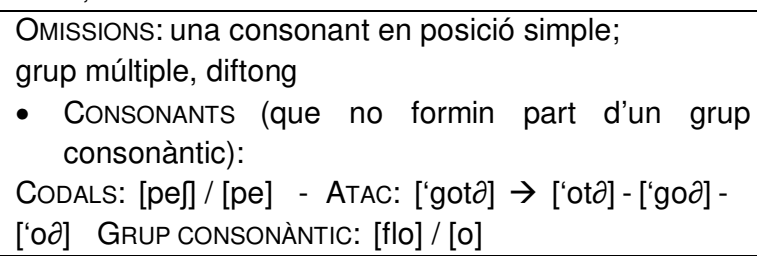 & \\
\hline & \multirow{3}{*}{ 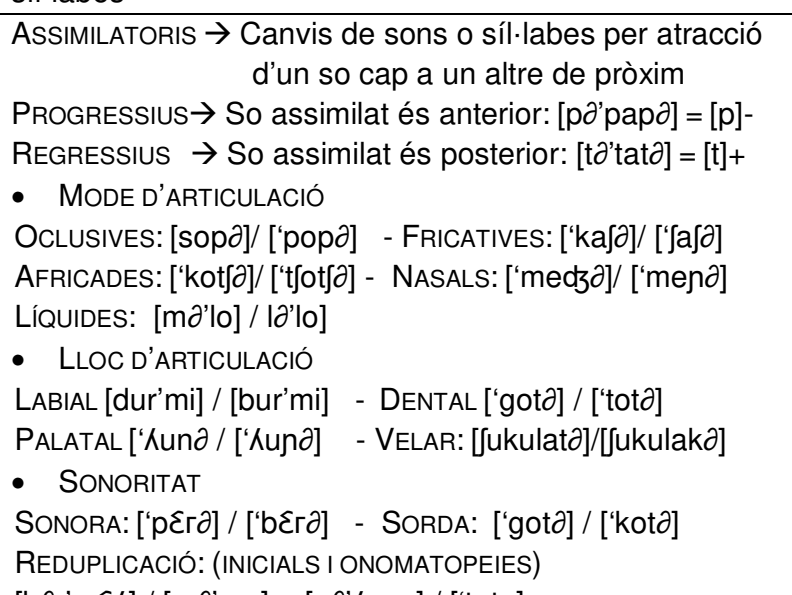 } & 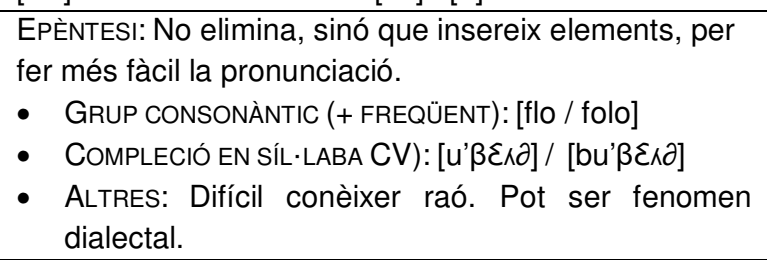 & \\
\hline & & 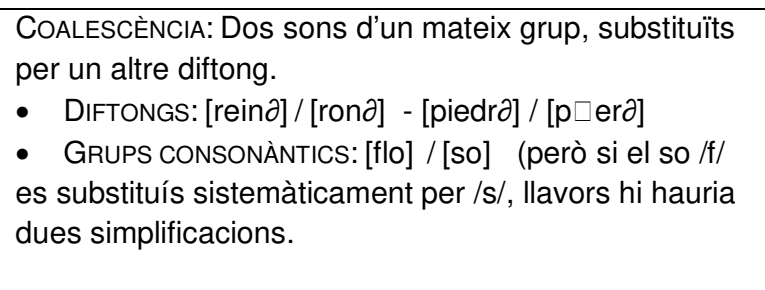 & \\
\hline & & $\begin{array}{l}\text { METÀTESI: Inversions en la seqüència de síl-laba, però } \\
\text { més aviat són un fenomen de paraula. } \\
\text { - SIL·LÀBICA: [mEl] / [IEm] }\end{array}$ & \\
\hline
\end{tabular}

Quadre 1. Processos de simplificació fonològica 
Per això el tipus de parla semiespontània ofereix realitzacions inesperades, no previstes ni pels models fonològics ni fonètics. És irregular i necessita analitzar-se a partir de tota la diversitat de la prosòdia, l'análisi acústica i melòdica, des d'una perspectiva que parteixi de la concepció de la competència comunicativa (Cantero, 2015). Això fa pensar en què gràcies a la interacció entre els interlocutors, presenta continuadament propietats emergents, ja que el resultat és la successió de noves estructures lingüístiques.

Un altre element que intervé en l'aprenentatge és el model oral a l'aula. Es podria comparar a una música de fons. És la parla de la mestra que l'infant sent a tothora, quan juga, parla, requereix, interactua amb ella i que, a part de donar-li seguretat i benestar, li facilita la percepció i la producció.

En aquesta interacció amb l'adult, l'infant s'acomoda al seu procés fonològic i s'hi va adaptant conforme identifica trets distintius i els reprodueix, però hi ha tot un camp a part del fonològic en què intervenen la fluïdesa, l'articulació, el timbre, l'entonació i la intel-ligibilitat d'un moment precís, que és quan posa en joc la seva competència comunicativa.

Tothom podríem situar-nos sota aquesta visió de la competència comunicativa per analitzar la nostra capacitat perceptiva i productiva en interacció amb una altra persona. Recentment, diversos investigadors van defugir de les metodologies tradicionals en els seus treballs sobre aprenentatge de llengües meta en estudiants de diverses edats, atenent els components prosòdics i sense la mediació de la llengua escrita, per verificar que era possible assolir uns objectius adequats, com així va ser, (Giralt, 2006; Bartolí, 2014; Spalacci, 2014).

Per analogia, un infant exposat a l'aprenentatge d'un model de llengua que sent a la llar d'infants, és de preveure que segueixi un patró similar, atès que no està encara alfabetitzat i les seves produccions reflecteixen el model de llengua de les seves mestres.

En conseqüència, la percepció de l'infant quan reprodueix la llengua que sent, també ha de demostrar un grau de coincidència elevat. Aquest analogia queda recollida en el quadre 2: 


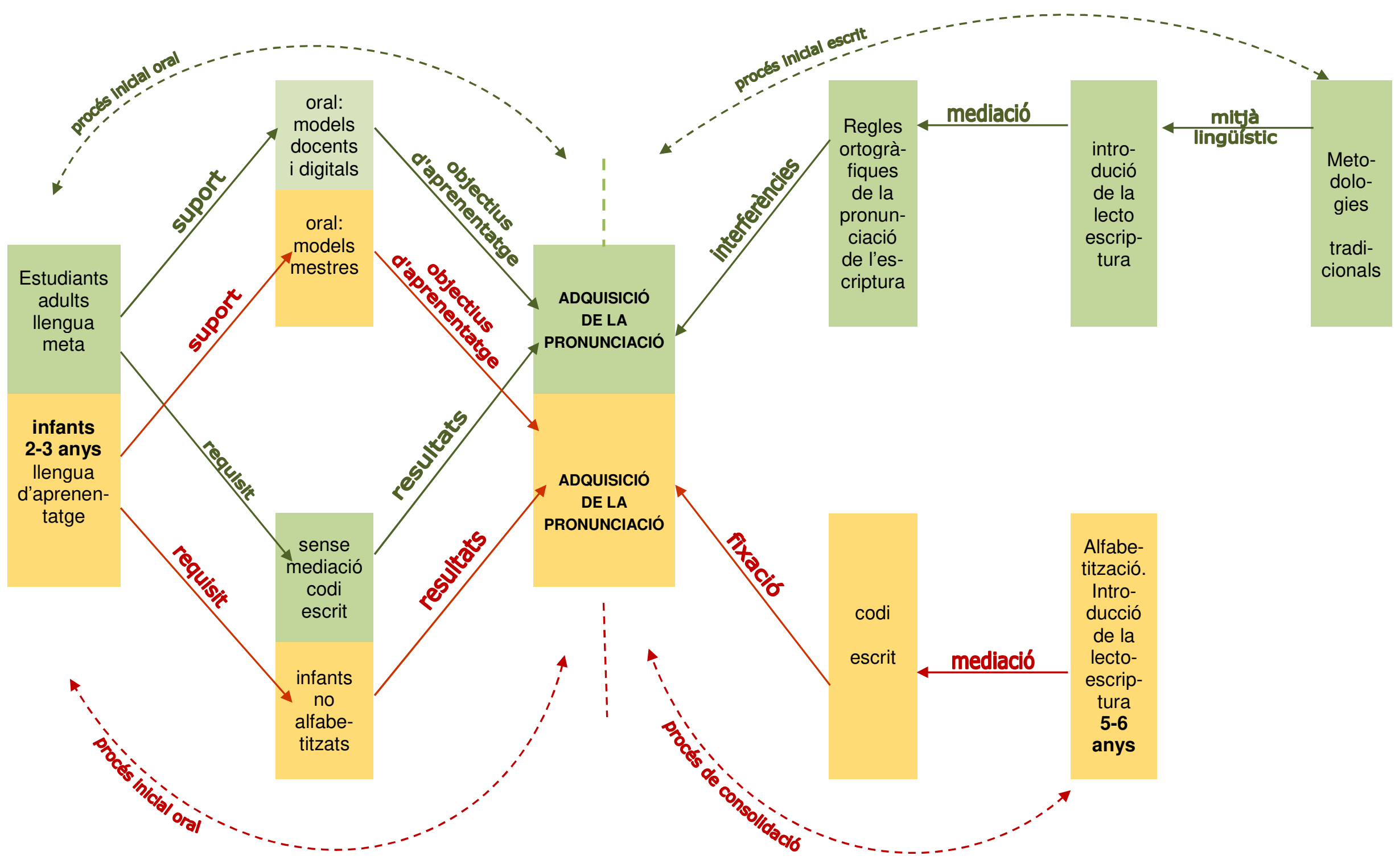

Quadre 2. Analogia de l'adquisició de la pronunciació mitjançant el codi oral, sense la mediació del codi escrit 


\section{OBJECTIUS}

En aquest treball s'han investigat les causes de les desviacions en la pronunciació de la parla dels infants de 2-3 anys, no alfabetitzats, sense dificultats fisiològiques ni físiques. Inicialment, com a punt de partida, es va creure que podrien ser degudes o bé a les característiques de la parla espontània o semiespontània o bé al desconeixement de la llengua escrita.

Des d'aquest punt de vista es van formular els següents objectius:

- Conèixer els factors que intervenen en la parla espontània quan els infants d'aquesta edat no reprodueixen amb fidelitat el model adult en la llengua que senten.

- Constatar la presència d'una correlació fonètica idèntica,que no correlació escrita idèntica.

- Obtenir una visió més global de les causes de les diferenciacions de la parla dels infants d'aquesta edat, tenint en compte les variables que es donen en el camp fonològic i que habitualment s'analitzen al laboratori de fonètica, com així també les pròpies del camp prosòdic, comprovables en el terreny de la parla espontània.

- Constatar la interrelació entre el procés de desenvolupament fonològic i els perfils fonològics ja coneguts, elaborats per edats i nivells.

- Els perfils sempre s'han orientat cap a la intervenció i reeducació i, gairebé mai, en relació als infants amb les capacitats lingüístiques, comunicatives i cognitives adequades, com és ara el cas.

- Comprovar si els tipus de processos de simplificació fonològica analitzats responen a les dels perfils estàndar, tipificats per edats i nivells, citats per diversos autors,

- Trobar el grau de correlació existent entre la percepció i la producció de la parla dels infants de 2-3 anys.

- Constatar que l'adult no s'adona de les seves diferenciacions de pronúncia respecte del model canònic i creu que quan l'infant el reprodueix fa diferències que associa amb processos de simplificació fonològica i no amb el model que ell mateix li forneix

\section{METODOLOGIA}

A la descripció de la metodologia, tenim en compte els omponents per situar la recerca en el seu context i els criteris metodològics per fer-ne una aplicació adequada.

Components:

- Espai. La llar d'infants on es va realitzar la investigació s'anomena Virgen del Pilar. Es troba situada al municipi de Sant Andreu de la Barca (Baix Llobregat).

- Mestres. La llar d'infants comptava amb dos grups d'infants de 2-3 anys, per la qual cosa la investigació es va fer als dos, així que van ser dues les mestres informants que van aportar els seus plantejaments pedagògics.

- Llengua social. La llengua castellana, atès que una gran majoria eren famílies de la resta de l'estat, així les úniques interlocutores per al català van ser les mestres.

- Selecció d'infants. Es va tenir cura que hi hagués el mateix nombre de nens que de nenes. A cada un se li va assignar un codi identificatiu per preservar la confidencialitat de la seva participació (infants del grup 1: L1; infants del grup 2: L2).

- Programacions de les mestres. Van ser analitzades acuradament i es va decidir que les sessions que les mestres en diuen racons i experimentacions serien les més idònies per fer els enregistraments de la recerca. 


\section{Criteris:}

Tenint en compte la importància de les activitats lingüístiques des de petits, a l'hora de triar-les es va partir dels criteris següents:

- Desenvolupar l'activitat en l'entorn de l'aula perquè fos un espai conegut per l'infant.

- Partir de l'experiència de l'infant, de manera que conegués l'activitat i l'hagués experimentada abans.

- Repetir de manera individual l'activitat triada feta anteriorment amb tot el grup d'infants, per tal de despertar l'activitat i motivació i afavorir la participació de l'infant en l'aprenentatge.

Comptant amb aquests criteris i amb el consens de les mestres, es van seleccionar les activitats que feien referència als següents tres tipus de textos, que van servir per fer els enregistraments.

Enregistraments:

- Text 1. La llegenda de Sant Jordi. Llegenda tradicional catalana, força coneguda pels infants. La mestra i l'infant van interactuar en conversa semiespontània amb el suport d'unes làmines que presentaven dibuixos sobre la llegenda.

- Text 2. Descripció d'un autor i la seva obra: Antoni Gaudí. Els infants havien treballat amb gomets el trencadís, a la sessió de racons. Per tant, la conversa semiespontània mestra-infant va ser adient i la mestra va fer servir també unes làmines que presentaven dibuixos sobre alguns edificis o detalls de l'obra d'Antoni Gaudí.

- Text 3. Cançons: Bon dia! i Els dies de la setmana. Aquestes eren cançons que interpretaven els infants en grup en arribar cada matí a la Llar. Van servir de tema de conversa per interactuar mestrainfant a l'hora de fer els enregistraments.

Cada mestra durant l'activitat individual va actuar lliurement i espontàniament, respectant la capacitat comunicativa de l'infant.

Els enregistraments orals de les primeres converses es van obtenir amb una gravadora convencional de veu. Cada infant va participar-hi tres vegades, una per a cada text. Després de fer una primera audició es va fer la corresponent transcripció escrita.

Per a l'obtenció de paraules es va fer una segona audició i amb ajuda del programa informàtic Praat, que permet segmentar fragments de so, es van identificar i seleccionar les paraules que haurien de servir per fer la mostra, a partir de les converses anteriors.

Aquestes paraules van ser classificades tant per infants com per mestres i grups. A continuació, es va fer la transcripció fonètica de cada paraula a partir de la realització d'un sonograma individual. Les dades obtingudes es van disposar en funció dels tres textos triats.

Pel que fa als arxius sonors obtinguts, van ser classificats en dos apartats, converses i paraules, diferenciats per grups d'infants, és a dir, es van aconseguir les següents mostres:

- $\quad 36$ converses, corresponents a 12 infants i 3 textos.

- 617 paraules. Aquesta mostra estava formada per 73 paraules diferents, cada una enregistrada tantes vegades com nombre d'infants la van pronunciar. 


\section{RESULTATS D’ANÀLISI DE LA MOSTRA}

A partir de l'anàlisi global de la mostra de paraules els resultats van ser presentats per informants, per paraules i per sons:

\subsection{Per informants}

A partir dels enregistraments orals, les transcripcions escrites i fonètiques i els sonogrames, es va fer una anàlisi fonètica inicial, obtenint una gran diversitat de fenòmens de diferenciació de les paraules respecte del model canònic, però molt coincidents amb el model de la mestra i es van fer per infants, mestres i grups d'infants. També a partir de les notes escrites, abundants, que s'havien recollit directament a l'aula al llarg del temps anterior a l'enregistrament.

\subsection{Per paraules}

La mostra de paraules dels tres textos presentava una gran diversitat, era atractiva per manipular-la, segmentar-la i disposar-la bé per analitzar-la. Per això es van seguir uns criteris de classificació que van permetre agrupar-les i estudiar-les.

Per reunir la informació que s'hi va descriure i tenir una visió de conjunt, es va fer una sèrie de taules de recollida de resultats de les 617 paraules que formaven el total de la mostra, o sigui, de les paraules pronunciades en interacció mestra-infant d'un grup i també les de la mateixa paraula de l'altre grup. Les taules van recollir les parelles de cada una de les paraules, en el benentès que hi ha una taula per a cada paraula amb la varietat de pronúncies mestra-infant dels dos grups.

A tall d'exemple, s'inclou una de les 73 taules elaborades que formen la totalitat del document, corresponent a la paraula [k $\partial \mathrm{s}^{\prime}$ te $\left.\lambda\right]$. A les columnes centrals hi ha les pronunciacions dels infants de cada grup; a banda i banda, les de les mestres respectives. (Taula 1).Els resultats van evidenciar que les paraules es podien agrupar segons els següents criteris:

- Repetides. Com tots els informants interactuaven amb els mateixos textos, les paraules clau eren gairebé les mateixes. Tal com s'ha dit anteriorment, es van obtenir 73 paraules iguals. L'estudi d'questa variable va permetre quantificar el nombre de produccions iguals que presentaven idèntiques desviacions del model canònic. Per exemple, la paraula $[\mathrm{k} \partial \mathrm{s}$ 'te $\lambda]$ va ser pronunciada per 5 infants del grup L1 i per 4 infants del grup L2.

- Per comparació. Com s'anava observant que la diversitat de pronúncies era majoritàriament un calc del model percebut, es va fer una altra classificació que facilités comparar les produccions de tots els informants junts. El resultat va mostrar, a més a més, que moltes vegades el model rebut pels infants no era només un únic model, perquè la mestra en produïa més d'un d'una mateixa paraula.

- Amb aquesta classificació es va obtenir una taula de pronúncies en què la transcripció fonètica venia a demostrar, que dintre del mateix grup d'infants gairebé sempre hi havia una pronunciació similar.

El conjunt de taules va permetre recollir les pronunciacions individuals de cada infant en interrelació amb la mestra d'un grup, però a la vegada incorporava també les de l'altre grup, en relació a la mateixa paraula. D'aquesta manera, es podia donar una mirada global a la paraula que es tractés, però de tots els informants a la vegada. Permetria veure les similituds i les diferències a analitzar. 


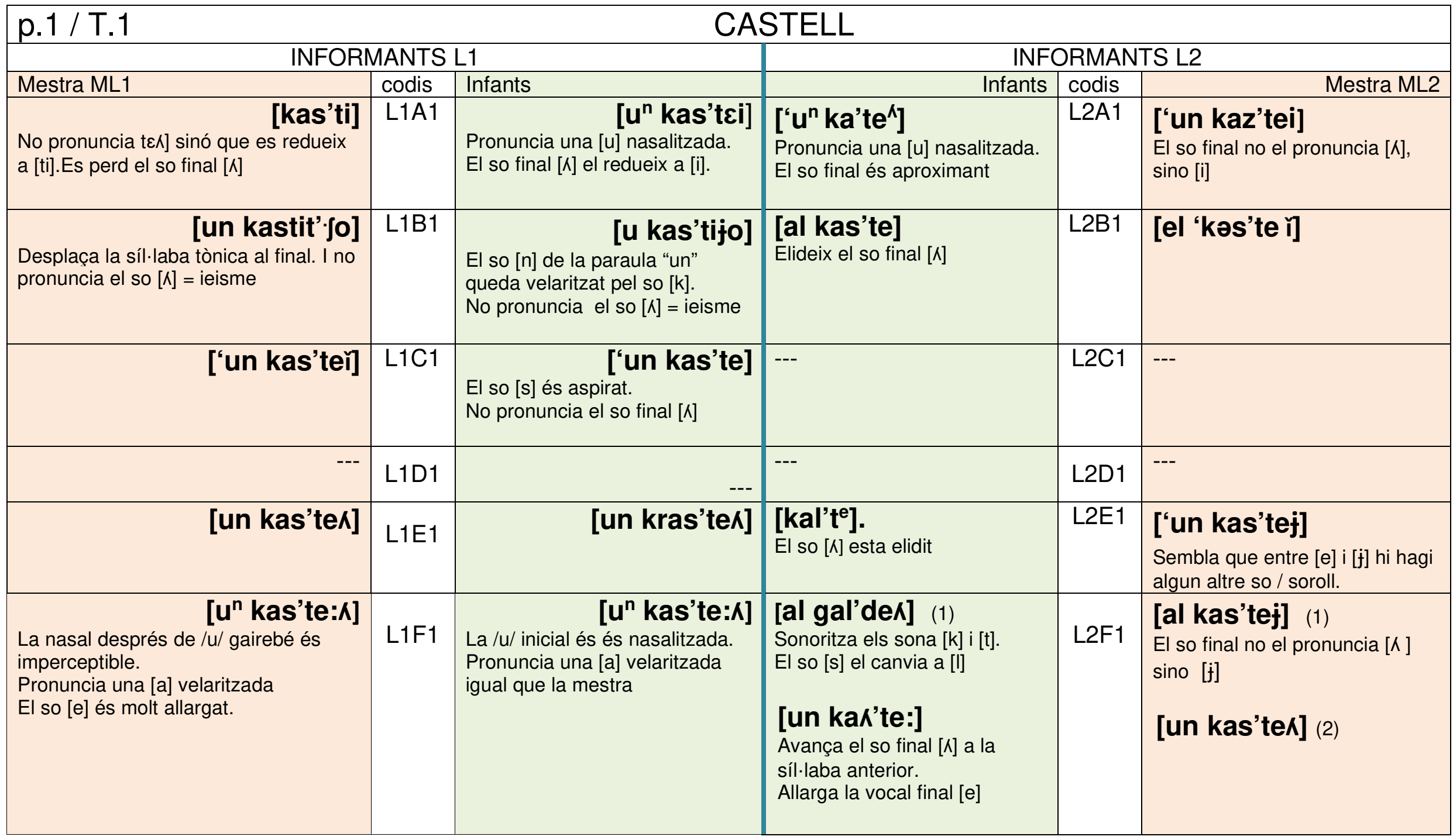

Taula 1. Paraules comparades i contrastades dels grups d'infants L1 + L2. Visió comparativa per paraules de les produccions de les mestres i infants (text 1) 
- Per analogia. Les comparacions anteriors van donar pas a observar les produccions sistemàtiques de paraules que coincidien, en diversos graus, entre la producció de la mestra i la percepció de l'infant. S'anava comprovant que les produccions de les mestres en parla semiespontània diferien del model canònic, i com els infants les percebien $\mathrm{i}$ al seu torn les produïen iguals $\mathrm{o}$ amb algunes diferències. L'analogia va permetre constatar pronunciacions per part dels infants diferenciades del model escrit, però idèntiques o gairebé idèntiques del model sonor rebut de la mestra.

- Per contrast. També es va constatar el contrast de pronunciacions entre la mestra i l'infant, perquè en alguns casos la diferència responia a cada pronúncia de la mestra amb la del seu infant interlocutor presentant ambdós algunes diferències respecte del model canònic per processos de simplificació fonològica o per altres components relacionats amb la prosòdia. En altres produccions el contrast no era de similitud sinó de desviació, perquè la coincidència no era absoluta i entrava en els graus d'aproximada o de no coincidència.

\subsection{Per sons}

Quan es va procedir a segmentar les paraules per conèixer el grau de fidelitat en les pronunciacions respecte del model canònic, es va fer de la manera següent:

- Per fonemes, grups consonàntics, vocals i diftongs en qualsevol posició en la paraula.

A partir del model canònic, es va fer una comparació dels sons produïts per les mestres, constatant que hi havia desviacions significatives pròpies de la parla espontània.

Es va fer la mateixa comparació en el cas dels sons pronunciats pels infants, per constatar el grau de fidelitat, tant amb el model canònic com amb el de la mestra i així observar quin segment o segments es desviaven. Tant en el cas de les mestres com en el dels infants es van aconseguir dades generalitzades i descriptives.

- Per sons en posició inicial al segment

Es va realitzar una classificació detallada atenent als sons en posició inicial al segment i afegint una subclassificació referida al mode d'articulació. Això valorava dos camps importants: la percepció i la producció de l'infant.

Per obtenir aquesta informació s'hi van incloure la pronunciació canònica, la de la mestra i la de l'infant. Així es va aconseguir una primera aproximació a les correlacions mestra-infant.

També es va quantificar quins eren els fonemes diferenciadors produïts pels informants quan no havien pronunciat els que eren canònicament correctes. A la vegada, es va fer un recompte de resultats per veure les incidències d'una manera quantitativa, és a dir, quins sons havien estat pronunciats de manera diferent $\mathrm{i}$ quines altres alternatives s'havien fet servir.

- Per sons en posició final al segment

Per tal de completar la classificació anterior i ja que es van seleccionar els segments de paraules i síl·labes en posició inicial, es va procedir a classificar els sons en posició final, fent servir el mateix procediment d'anàlisi que en el cas anterior.

- Per graus de coincidència

Representa una nova i més detallada classificació de les paraules. Es va establir la següent jerarquia o graus de coincidència entre parelles de paraules iguals en correlació mestra-infant: 


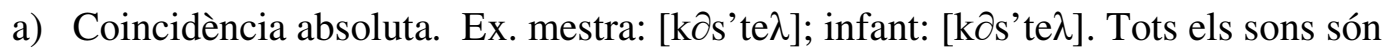
coincidents.

b) Coincidència aproximada. Ex. mestra: [an'toni $\gamma$ au' $\boldsymbol{\delta} \mathbf{i}$ ]; infant: [an'toni $\gamma$ ai' $\boldsymbol{\delta} \mathbf{i}$ ]. En el cas que hi hagués només un sol so diferent.

c) No coincidència. Ex. mestra [panza' $\boldsymbol{\delta}$ o]; infant: [kenja' $\boldsymbol{\delta}$ or]. Hi havia un canvi d'oclusiva de $[\mathrm{p}]$ a [k], una semiconsonantització de [3] a [j] i una epèntesi final [r].

d) Producció d'un doble fenomen:

a. Correcció de la producció de la mestra per part de l'infant. Ex. mestra: [por]; infant: [po].

b. Substitució de la producció de la mestra, amb un castellanisme, per part de l'infant. Ex. mestra: [fok]; infant: [vweyo].

Vaig observar que les coincidències absolutes estaven molt igualades en nombre amb les de les coincidències aproximades. Primer, era un resultat gairebé esperat d'acord amb la línia d'anàlisis que havia realitzat al principi, però com que les coincidències considerades aproximades només presentaven un so divergent en les correspondències, i moltes vegades es tractava d'un canvi poc significatiu per reducció, omissió, sonorització, etc., vaig considerar que les coincidències aproximades eren gairebé absolutes o molt ajustades a aquest grau.

El grau de les no coincidències era diferent, perquè representaven quasi una tercera part del total de paraules analitzades. Ara bé, cal tenir en compte que en aquest grau s'hi trobaven classificades les paraules que tenien divergència amb el model de la mestra a partir de 2, 3, 4, o més sons. Llavors, es va considerar que no era pertinent el fet de valorar igual una paraula amb dues diferències que una altra amb quatre o més. Per tant, només que em fixés en les paraules amb dues diferències del tipus que abans he esmentat, que gairebé eren la meitat del total d'aquest grau, es podrien considerar aproximades, amb la qual cosa el nombre de paraules classificades com a no coincidències quedaria ostensiblement més reduït.

Les correccions per part de l'infant a la pronúncia de la mestra o els castellanismes enregistrats, no van ser rellevants ni el seu nombre significatiu, sinó que van ser paraules obtingudes 6 o 7 vegades pel cap alt.

La quantificació dels graus de coincidències absolutes, aproximades o no coincidències de totes les paraules i de l'anàlisi quantitativa per percentatges, va corroborar l'anàlisi qualitativa prèvia, tal com es pot llegir a la taula 2.

La valoració general segons aquests resultats en percentatges va permetre observar que hi va haver una sincronia entre els grups d'informants (L1 i L2) i entre el contingut dels tres textos, els quals van mantenir una influència similar en cada situació comunicativa.

Les coincidències absolutes i les aproximades van ser molt equiparables. Si se li afegeixen les no coincidents, tenint en compte el matís del nombre o quantitat de sons diferents que els infants han produït en una mateixa paraula, respecte del model imitat, es podria parlar d'un 90\%, abans comentat. Aquest $90 \%$ representaria el percentatge d'imitació del model que els infants van percebre i que després van produir 


\begin{tabular}{|c|c|c|c|c|c|c|c|c|c|c|c|}
\hline \multicolumn{4}{|c|}{ ML1 text 1} & \multicolumn{4}{|c|}{ ML2 text 1} & \multicolumn{4}{|c|}{ Totals L1 + L2 } \\
\hline $\mathrm{CAb}$ & CAp & $\mathrm{NC}$ & $\mathrm{CC}$ & $\mathrm{CAb}$ & CAp & $\mathrm{NC}$ & $\mathrm{CC}$ & $\mathrm{CAb}$ & CAp & $\mathrm{NC}$ & $\mathrm{CC}$ \\
\hline 27 & 18 & 20 & 2 & 18 & 21 & 13 & 3 & 45 & 39 & 33 & 5 \\
\hline $40,29 \%$ & $\begin{array}{l}26,86 \\
\%\end{array}$ & $29,86 \%$ & $\begin{array}{l}2,98 \\
\%\end{array}$ & $32,72 \%$ & $38,18 \%$ & $23,63 \%$ & $5,45 \%$ & $37 \%$ & $32 \%$ & $27 \%$ & $4 \%$ \\
\hline \multicolumn{4}{|c|}{ Total paraules grup L1: 67} & \multicolumn{4}{|c|}{ Total paraules grup L2: 55} & \multicolumn{4}{|c|}{ Total paraules L1+L2: 122} \\
\hline
\end{tabular}

\begin{tabular}{|l|l|l|l||l|l|l|l||l|l|l|l|}
\hline \multicolumn{1}{|l||}{ ML1 text 2 } & \multicolumn{1}{|l||}{ ML2 text 2 } & \multicolumn{1}{l|}{ Totals L1 + L2 } \\
\hline CAb & CAp & NC & CC & CAb & CAp & NC & CC & CAb & CAp & NC & CC \\
\hline 10 & 10 & 16 & 0 & 16 & 14 & 17 & 1 & 26 & 24 & 33 & 1 \\
\hline & $\begin{array}{l}27,78 \\
27,78 \%\end{array}$ & $44,44 \%$ & - & $33,33 \%$ & $29,16 \%$ & $35,41 \%$ & $2,09 \%$ & $31 \%$ & $28 \%$ & $39 \%$ & $1 \%$ \\
\hline
\end{tabular}

\begin{tabular}{|c|c|c|c|c|c|c|c|c|c|c|c|}
\hline \multicolumn{4}{|c|}{ ML1 text 3} & \multicolumn{4}{|c|}{ ML2 text 3} & \multicolumn{4}{|c|}{ Totals L1 + L2 } \\
\hline $\mathrm{CAb}$ & CAp & $\mathrm{NC}$ & $\mathrm{CC}$ & $\mathrm{CAb}$ & CAp & $\mathrm{NC}$ & $\mathrm{CC}$ & $\mathrm{CAb}$ & CAp & $\mathrm{NC}$ & $\mathrm{CC}$ \\
\hline 15 & 34 & 22 & 0 & 12 & 21 & 6 & 1 & 27 & 55 & 28 & 1 \\
\hline $39,39 \%$ & $\begin{array}{l}28,79 \\
\%\end{array}$ & $27,27 \%$ & $4,54 \%$ & $27,27 \%$ & $41,82 \%$ & $27,27 \%$ & $3,63 \%$ & $33 \%$ & $34 \%$ & $27 \%$ & $4 \%$ \\
\hline \multicolumn{4}{|c|}{ Total paraules grup L1: 71} & \multicolumn{4}{|c|}{ Total paraules grup L2: 40} & \multicolumn{4}{|c|}{ Total paraules L1+L2 : 111} \\
\hline
\end{tabular}

\begin{tabular}{|c|c|c|c|c|c|c|c|c|c|c|c|}
\hline \multicolumn{4}{|c|}{ ML1 textos $1,2,3$} & \multicolumn{4}{|c|}{ ML2 textos $1,2,3$} & \multicolumn{4}{|c|}{ Totals L1 + L2 textos $1,2,3$} \\
\hline $\mathrm{CAb}$ & CAp & $\mathrm{NC}$ & $\mathrm{CC}$ & $\mathrm{CAb}$ & CAp & $\mathrm{NC}$ & $\mathrm{CC}$ & $\mathrm{CAb}$ & CAp & $\mathrm{NC}$ & $\mathrm{CC}$ \\
\hline 52 & 62 & 58 & 2 & 46 & 56 & 36 & 5 & 98 & 118 & 94 & 7 \\
\hline $29,90 \%$ & $35,63 \%$ & $33,33 \%$ & $\begin{array}{c}1,15 \\
\%\end{array}$ & $32,16 \%$ & $39,16 \%$ & $25,17 \%$ & 3,49 & $31 \%$ & $37 \%$ & $30 \%$ & $2 \%$ \\
\hline \multicolumn{4}{|c|}{ Total paraules grup L1: 174} & \multicolumn{4}{|c|}{ Total paraules grup L2: 143} & \multicolumn{4}{|c|}{ Total paraules L1+L2 : 317} \\
\hline
\end{tabular}

Taula 2. Percentatges de resultats globals de les paraules en correlació infants-mestres, textos 1,2,3, segons graus de coincidència: COINCIDÈNCIA ABSOLUTA (CAb); APROXIMADA (CAp); NO COINCIDÈNCIA (NC); CORREGIDA/ CASTELLANISME (CC). 
Si pel contrari, deixéssim d'incloure aquest grup de no coincidències, vindria a representar només un $30 \%$ de característiques diferenciadores en correlació infants-mestra, que com es veurà a l'anàlisi estadística no té una rellevància important respecte del total.

Igualment, la distribució total en percentatges, també per grups, va ser pràcticament homogènia i va ser la següent:

Grup L1: Coincidències absolutes $29,90 \%$, coincidències aproximades $35,63 \%$, no coincidències $33,33 \%$ i correccions/castellanismes $1,15 \%$.

Grup L2: Coincidències absolutes 32,16\%, coincidències aproximades $39.16 \%$, no coincidències $25,17 \%$ i correccions/castellanismes $3,49 \%$.

Aquests resultats vaig completar-los amb els obtinguts a partir de les análisis dels processos de simplificació fonològica, com s'exposarà al següent apartat.

L'anàlisi va donar a conèixer els graus de coincidència ja esmentats. Si l'anàlisi donés un grau de coincidència absoluta entre la mestra i l'infant, aquesta dada seria demostrativa que la percepció i la producció de l'infant havia estat l'esperada. Ara bé en els casos en què no hi hagués coincidència o fos aproximada, caldria saber-ne el perquè, és a dir caldria esbrinar-ne les causes que l'havien originat. Per això va ser necessari fer l'anàlisi de sons en correlació mestra-infant de manera encara més detallada.

- Per processos de simplificació fonològica a nivell de paraula, de síl·laba i de segment.

Cal recordar que existeixen diverses classificacions per analitzar-los, i també una sèrie de perfils per nivells $\mathrm{i}$ edats per planificar la reeducació del component fonològic desviat, si procedeix. Actualment aquests perfils s'apliquen tenint en compte els tres nivells o components de la fonologia jeràrquica: l'estructura de la paraula, de la síllaba i el nivell segmental. Per tant, a l'anàlisi de la mostra de paraules se li va aplicar aquesta jerarquia per considerar-la menys tradicional i més completa per entendre millor les singularitats dels informants, en interacció, segons els textos 1,2,3 i el grup on eren.

L'objectiu era conèixer l'existència de processos de simplificació fonològica en les mostres analitzades dels infants, efectuant al mateix temps una correlació amb les mostres obtingudes de les mestres.

A partir del recull dels aproximadament vuitanta processos de simplificació fonològica, es van analitzar cada una de les 617 paraules de la mostra per conèixer quin d'aquests processos s'havia realitzar tant a nivell de paraula, com de síl-laba i segment. A nivell de paraula se'n van observar relativament pocs; a nivell de síl-laba els infants van realitzar-ne més i a nivell de segment, molts més.

De fet, avui dia es compta amb diversos models per a l'anàlisi dels processos de naturalesa simplificadora i d'uns perfils per nivells i per edats, que venen a ser una eina de línia preventiva, per fer una avaluació inicial i després planificar l'eventual reeducació del component fonològic substituït o absent de l'infant. El tractament de la mostra de paraules analitzades va estar subjecte a la classificació jeràrquica de paraula, síllaba i segment (Serra, 2004; Bosch, 2004; Miras, 1992). 
- A nivell de paraula:

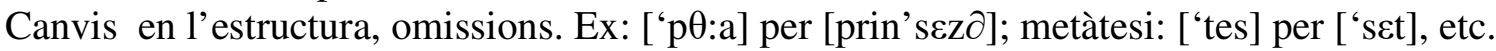

- A nivell de síl·laba:

Reduccions en l'atac, el nucli o la coda, diftongs, grups consonàntics. Ex. [di'meka] per [di'mekras]. Omissions de consonants en l'atac, el nucli o la coda, grups consonàntics. Ex: [di'zo] per [di'zous]. Epèntesi. Ex: [kan'son] per [kan'so]

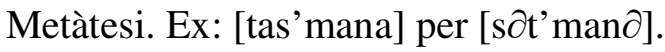

- A nivell segmental:

Mode d'articulació. Ex: [la'jenda] per [la'zenda], semiconsonantització.

Lloc d'articulació. Ex: ['boӨa] per ['bosa], prominència de la llengua.

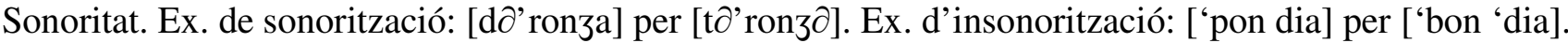

Tant en el cas dels graus de coincidència com en l'anterior dels processos de simplificació fonològica es va fer un càlcul quantitatiu, primer en percentatges, que es mostra a la taula 3 , i després estadísticament, tal com s'exposa al següent apartat.

\subsection{Anàlisis estadístiques}

Totes les dades globals en percentatges per grups i textos que presenten les taules anteriors 2 i 3 , es van verificar amb una eina d'anàlisi estadística, la de variança ANOVA, d'un factor.

Les continuades comparacions infant-mestra, van reflectir que a l'hora de comparar informants, grups, textos, paraules, graus de coincidència i processos de simplificació, sempre s'obtenien resultats en paral·lel, la qual cosa facilitava la seva interpretació.

\subsubsection{Comparació de grups i mestres}

Un aspecte important per la incidència que podia tenir en la interpretació dels resultats era conèixer si els dos grups es podrien considerar homogenis o no, atès que la mostra de paraules havia estat sotmesa a diferents tractaments i si es volia verificar la hipòtesi en sentit positiu, el resultat havia de ser paral·lel als dos grups. Precisament per això, s'havia tingut molta cura de considerar els dos grups de forma independent i sempre es va analitzar la mostra de paraules amb una precisió semblant als dos grups.

Els resultats obtinguts, segons les dades que s'han exposat a les taules 2 i 3 i que han estat sotmeses a anàlisi estadística, permet considerar que els dos grups han estat similars. Tant és així que es podrien considerar com un sol grup. Els percentatges inicials ho anaven també indicant, però amb aquesta anàlisi estadística és evident que les quantitats no van presentar diferències rellevants, com es veurà als comentaris sobre els graus de coincidència de produccions en correlació infants mestres.

Al mateix temps, això va evidenciar que la influència de la mestra va ser la mateixa, cada una respecte del seu grup d'infants. 


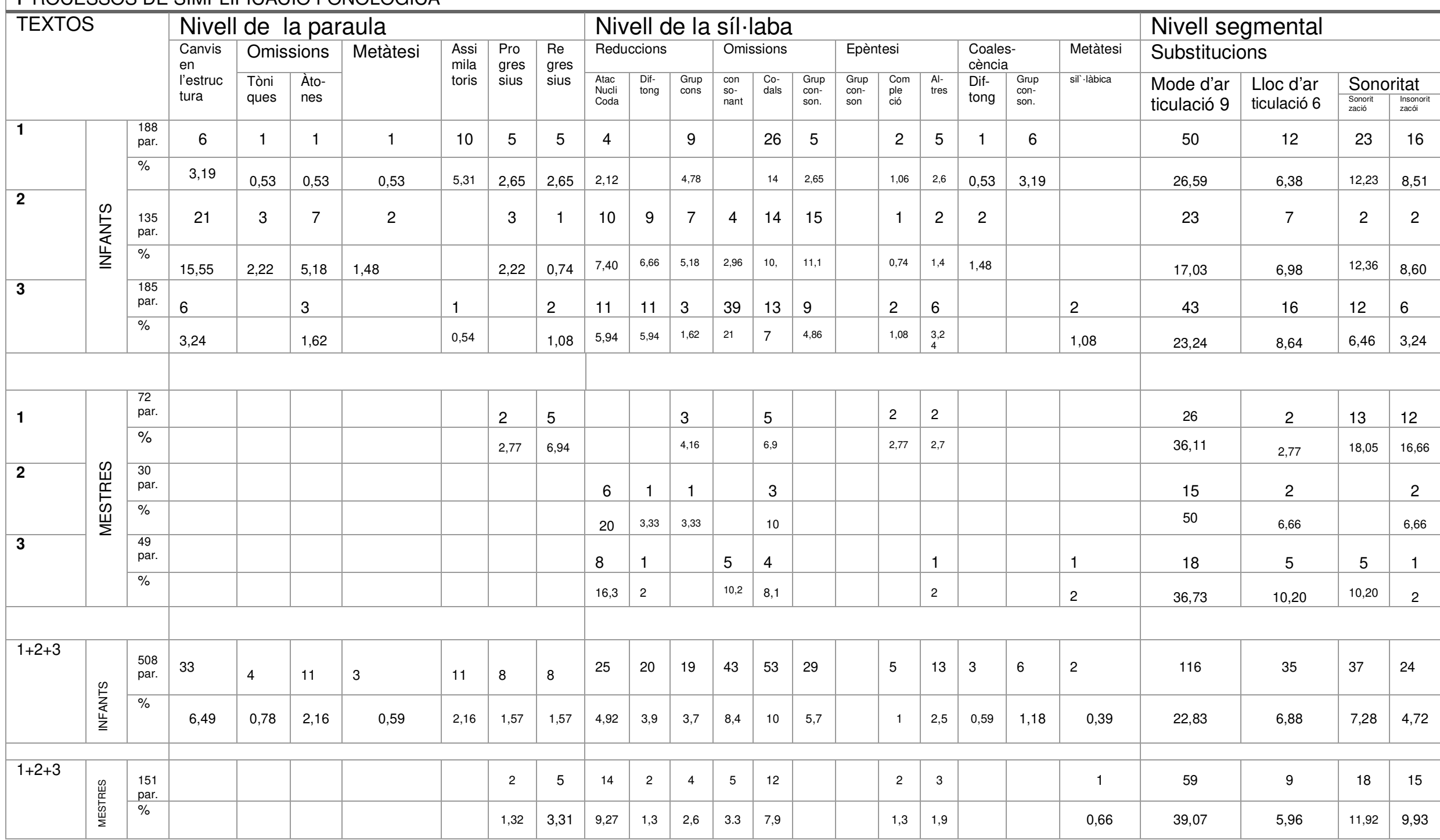

Taula 3. Percentatges de resultats globals del nombre de processos de simplificació fonològica en correlació infants-mestres, textos 1,2,3. 


\subsubsection{Correlació entre resultats}

A partir dels percentatges introduïts de les taules, quant als graus de coincidència, els resultats de correlació es van obtenir per a cada una d'elles, sistemàticament. Els resultats són:

\subsubsection{Coincidències absolutes}

A la taula següent, sobre el grau de Coincidències Absolutes en correlació infants-mestra, l'anàlisi demostra que no hi ha diferències entre els dos grups. Es pot comprovar que els percentatges són molt equivalents i les diferències més aviat els equilibren, que no els diferencien.

ANÀLISI DE LA VARIANÇA D'UN FACTOR
Resum
\begin{tabular}{|l|r|r|r|r|}
\hline Grups & Compte & Suma & Promig & \multicolumn{1}{c|}{ Variança } \\
\hline Columna 1 & 3 & 107,17 & 35,72 & 47,41 \\
\hline Columna 2 & 3 & 93,32 & 31,10 & 11,13 \\
\hline
\end{tabular}

\begin{tabular}{|c|c|c|c|c|c|c|}
\hline \multicolumn{7}{|c|}{ ANÅLISI DE LA VARIANÇA } \\
\hline $\begin{array}{c}\text { Origen de les } \\
\text { variacions }\end{array}$ & $\begin{array}{l}\text { Suma de } \\
\text { quadrats }\end{array}$ & $\begin{array}{l}\text { Graus de } \\
\text { llibertat }\end{array}$ & $\begin{array}{c}\text { Promig dels } \\
\text { quadrats }\end{array}$ & $F$ & Probabilitat & $\begin{array}{c}\text { Valor crític } \\
\text { per a } F\end{array}$ \\
\hline Entre grups & 31,97 & 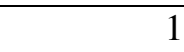 & 31,97 & 1,09 & 0,35 & 7,70 \\
\hline $\begin{array}{l}\text { Dintre dels } \\
\text { grups }\end{array}$ & 117,09 & 4 & 29,27 & & & \\
\hline Total & 149,06 & 5 & & & & \\
\hline
\end{tabular}

Taula 4. Resultats $i$ anàlisi estadística. Coincidències absolutes.

L'anàlisi de la variança corrobora que no hi ha diferències significatives, ja que l'índex F 1,09 és menor al valor crític 7,70. Igualment, no n'hi ha degut a què l'índex de probabilitat 0,35 és més alt que 0,05 .

\subsubsection{Coincidències aproximades}

Pel que fa al grau de Coincidències Aproximades en correlació infants-mestra, l'anàlisi demostra que tampoc no hi ha diferències entre els dos grups. Es pot comprovar que els percentatges obtinguts són força equivalents i no hi ha diferències rellevants, per la qual cosa són estadísticament comparables.

\begin{tabular}{|c|c|c|c|c|}
\hline \multicolumn{5}{|c|}{$\begin{array}{l}\text { ANÀLISI DE LA VARIANÇA D’UN FACTOR } \\
\text { Resum }\end{array}$} \\
\hline Grups & Compte & Suma & Promig & Variança \\
\hline Columna 1 & 3 & 83,43 & 27,81 & 0,93 \\
\hline Columna 2 & 3 & 109,16 & 36,38 & 42,48 \\
\hline
\end{tabular}




\begin{tabular}{|c|c|c|c|c|c|c|}
\hline \multicolumn{7}{|c|}{ ANÀLISI DE LA VARIANÇA } \\
\hline $\begin{array}{c}\text { Origen de les } \\
\text { variacions }\end{array}$ & $\begin{array}{l}\text { Suma de } \\
\text { quadrats }\end{array}$ & $\begin{array}{l}\text { Graus de } \\
\text { llibertat }\end{array}$ & $\begin{array}{c}\text { Promig dels } \\
\text { quadrats }\end{array}$ & $F$ & Probabilitat & $\begin{array}{c}\text { Valor crític } \\
\text { per a } F\end{array}$ \\
\hline Entre grups & 110,33 & (a) & 110,33 & 5,08 & 0,08 & 7,70 \\
\hline $\begin{array}{l}\text { Dintre dels } \\
\text { grups }\end{array}$ & 86,82 & 4 & 21,70 & & & \\
\hline Total & 197,164 & 5 & & & & \\
\hline
\end{tabular}

Taula 5. Resultats $i$ anàlisi estadística. Coincidències aproximades.

L'anàlisi de la variança també ho corrobora indicant que l'índex F 5,08 que és menor al valor crític 7,70. Per tant no hi ha diferències significatives. De la mateixa manera, l'índex de probabilitat 0,08 és més alt que 0,05. Les dues dades confirmen l'absència de diferències entre els grups.

\subsubsection{Textos usats en la mostra de paraules}

A la metodologia es va fer una descripció del tipus de textos que en consens amb les mestres havíem seleccionat, però calia saber si hi hauria diferència de resultats a causa de la diferència de tipologia, de vocabulari, de dificultat entre ells. Sobretot perquè dos d'ells eren molt coneguts pels infants en les activitats diàries (Cançons); o en la tradicional anual (Llegenda de Sant Jordi); però el menys conegut era el text 3: Antoni Gaudí i la seva obra, el qual es va treballar puntualment a l'aula en relació als colors del trencadís i a altres exercicis més manipulatius.

L’anàlisi estadística va mostrar això:

\begin{tabular}{|c|c|c|c|c|}
\hline \multicolumn{5}{|c|}{$\begin{array}{l}\text { ANÀLISI DE LA VARIANÇA D’UN FACTOR } \\
\text { Resum }\end{array}$} \\
\hline Grups & Compte & Suma & Promig & Variança \\
\hline Text 1 & 4 & 99,97 & 24,99 & 210,32 \\
\hline Text 2 & 4 & 99,99 & 24,99 & 272,99 \\
\hline Text 3 & 4 & 99,99 & 24,99 & 204,61 \\
\hline
\end{tabular}

\begin{tabular}{|c|c|c|c|c|c|c|}
\hline \multicolumn{7}{|c|}{ ANÀLISI DE LA VARIANÇA } \\
\hline $\begin{array}{c}\text { Origen de les } \\
\text { variacions }\end{array}$ & $\begin{array}{l}\text { Suma de } \\
\text { quadrats }\end{array}$ & $\begin{array}{l}\text { Graus de } \\
\text { llibertat }\end{array}$ & $\begin{array}{l}\text { Promig dels } \\
\text { quadrats }\end{array}$ & $F$ & Probabilitat & $\begin{array}{l}\text { Valor crític } \\
\text { per a } F\end{array}$ \\
\hline Entre grups & 6,66 & 2 & 3,33 & 1,45 & 0,99 & 4,25 \\
\hline $\begin{array}{l}\text { Dintre dels } \\
\text { grups }\end{array}$ & 2063,79 & 9 & 229,31 & & & \\
\hline Total & 2063,79 & 11 & & & & \\
\hline
\end{tabular}

Taula 6. Resultats $i$ anàlisi estadística. Comparació entre textos 
L'anàlisi estadística va demostrar que no hi havia diferències significatives entre els textos 1,2,3. Les dades globals indiquen en cada grau de coincidències que tots van tenir un comportament similar, és a dir, fins i tot en el grau de no coincidències que és el màxim exponent de diferenciacions, el percentatge també va ser pràcticament igual en els tres textos.

L'anàlisi de variança també ho corrobora indicant que l'índex F 1,45 és menor al valor crític 4,25. Per tant no hi ha diferències significatives. De la mateixa manera, l'índex de probabilitat 0,99 és més alt que 0,05. En resum, els dos resultats confirmen que entre els tres textos no hi ha diferències significatives.

\subsubsection{Processos de simplificació fonològica.}

Aquesta mateixa anàlisi estadística de variança ANOVA es va aplicar als percentatges obtinguts en els Processos de Simplificació Fonològica en correlació infants-mestres.

Els percentatges treballats pel que fa a nivell de paraula es van descartar perquè no presentaven pràcticament dades estadísticament significatives.

Ara bé a nivell segmental, és el valor que recollia els processos de simplificació més abundants en el mode i lloc d'articulació i en sonoritzacions.

Es va fer l'anàlisi estadística en correlació infants-mestres en aquest nivell i els resultats van demostrar que no hi havia diferències rellevants entre grups d'informants. Les dades obtingudes són molt semblants i no ofereixen cap dubte a l'hora d'inferir les causes d'aquests processos de simplificació fonològica, que tal com he dit tenen el marc comunicatiu de la conversa semiespontània i en són un reflex de les característiques que són pròpies a aquest tipus de parla.

Tal com es pot comprovar, en el cas dels infants l'índex F 0,16 és menor al valor crític 4,25. Per tant no hi ha diferències significatives. De la mateixa manera, l'índex de probabilitat 0,85 és més alt que 0,05 .

A continuació, transcric les dades corresponents:

\section{DADES PERCENTUALS DELS PROCESSOS DE SIMPLIFICACIÓ FONOLÒGICA DELS DOS GRUPS, PER INFANTS}

\begin{tabular}{|l|c|c|c|c|}
\hline \multicolumn{5}{|c|}{ NIVELL SEGMENTAL / Infants } \\
\hline & $\begin{array}{c}\text { Mode } \\
\text { d'articulació }\end{array}$ & $\begin{array}{c}\text { Lloc } \\
\text { d'articulació }\end{array}$ & Sonorització & insonorització \\
\hline Text 1 & 26,59 & 6,38 & 12,23 & 8,51 \\
\hline Text 2 & 17,03 & 6,98 & 12,36 & 8,6 \\
\hline Text 3 & 23,24 & 8,64 & 6,46 & 3,24 \\
\hline
\end{tabular}

\begin{tabular}{|c|c|c|c|c|}
\hline \multicolumn{5}{|c|}{$\begin{array}{l}\text { ANÀLISI DE LA VARIANÇA D’UN FACTOR } \\
\text { Resum }\end{array}$} \\
\hline Grups & Compte & Suma & Promig & Variança \\
\hline Fila 1 & 4 & 53,71 & 13,42 & 82,84 \\
\hline Fila 2 & 4 & 44,97 & 11,24 & 19,96 \\
\hline Fila 3 & 4 & 41,58 & 10,39 & 78,25 \\
\hline
\end{tabular}




\begin{tabular}{|l|r|r|r|r|r|r|}
\hline \multicolumn{2}{|c|}{ ANÀLISI DE LA VARIANÇA } & \multicolumn{1}{|l|}{} & $\begin{array}{c}\text { Valor crític } \\
\text { per a F }\end{array}$ \\
\hline $\begin{array}{l}\text { Origen de les } \\
\text { variacions }\end{array}$ & $\begin{array}{c}\text { Suma de } \\
\text { quadrats }\end{array}$ & $\begin{array}{c}\text { Graus de } \\
\text { llibertat }\end{array}$ & $\begin{array}{c}\text { Promig dels } \\
\text { quadrats }\end{array}$ & $F$ & 0,85 & 4,25 \\
\hline Entre grups & 19,58 & 2 & 9,79 & 0,16 & & \\
\hline $\begin{array}{l}\text { Dintre dels } \\
\text { grups }\end{array}$ & 543,18 & 9 & 60,35 & & & \\
\hline Total & 562,76 & 11 & & & & \\
\hline
\end{tabular}

Taula 7. Resultats $i$ anàlisi estadística. Processos de simplificació fonològica. Nivell segmental. Infants.

En el cas de les mestres, l'index F $(0,043)$, també és menor al valor crític $(4,25)$ i l'índex de probabilitat $(0,95)$ és igualment més alt que 0,05 .

A continuació s'inclouen els resultats de l'anàlisi estadística pel que fa a les mestres.

\section{DADES PERCENTUALS DELS PROCESSOS DE SIMPLIFICACIÓ FONOLÒGICA DELS DOS GRUPS, PER MESTRES}

\begin{tabular}{|l|c|c|c|c|}
\hline \multicolumn{2}{|l|}{ NIVELL SEGMENTAL / mestres } \\
\hline & $\begin{array}{c}\text { Mode } \\
\text { d'articulació }\end{array}$ & $\begin{array}{c}\text { Lloc } \\
\text { d'articulació }\end{array}$ & Sonorització & insonorització \\
\hline Text 1 & 36,11 & 2,77 & 18,05 & 16,66 \\
\hline Text 2 & 50,00 & 6,66 & 0 & 6,66 \\
\hline Text 3 & 36,73 & 10,20 & 10,20 & 2,00 \\
\hline
\end{tabular}

\begin{tabular}{|c|c|c|c|c|}
\hline \multicolumn{5}{|c|}{$\begin{array}{l}\text { ANÀLISI DE LA VARIANÇA D’UN FACTOR } \\
\text { Resum }\end{array}$} \\
\hline Grups & Compte & Suma & Promig & Variança \\
\hline Fila 1 & 4 & 73,59 & 18,39 & 187,03 \\
\hline Fila 2 & 4 & 63,32 & 15,83 & 528,78 \\
\hline Fila 3 & 4 & 59,13 & 14,78 & 229,02 \\
\hline
\end{tabular}

\begin{tabular}{|l|r|r|r|r|r|r|}
\hline \multicolumn{2}{|c|}{ ANÀLISI DE LA VARIANÇA } \\
\hline $\begin{array}{l}\text { Origen de les } \\
\text { variacions }\end{array}$ & $\begin{array}{c}\text { Suma de } \\
\text { quadrats }\end{array}$ & $\begin{array}{c}\text { Graus de } \\
\text { llibertat }\end{array}$ & $\begin{array}{c}\text { Promig dels } \\
\text { quadrats }\end{array}$ & $F$ & Probabilitat & $\begin{array}{c}\text { Valor crític } \\
\text { per a } F\end{array}$ \\
\hline Entre grups & 27,67 & 2 & 13,83 & 0,04 & 0,95 & 4,25 \\
\hline $\begin{array}{l}\text { Dintre dels } \\
\text { grups }\end{array}$ & 2834,53 & 9 & 314,94 & & & \\
\hline Total & 2862,20 & 11 & & & & \\
\hline
\end{tabular}

Taula 8. Resultats i anàlisi estadística. Processos de simplificació fonològica. Nivell segmental. Mestres.

Per tant, la correlació infants-mestres a nivell segmental, pel que fa a la simplificació dels processos fonològics té una alta coincidència i no presenta diferències significatives entre els grups. 
A nivell de síl·laba el resultat de l'anàlisi estadística demostra una correlació raonablement alta infants mestres del 0,70. Aquesta dada s'allunya una mica del valor màxim que és 1 . Ara bé, no es pot interpretar aquest valor des d'un punt de vista estrictament numèric, ja que en la parla espontània molts dels fenòmens inclosos en aquest nivell de síl-laba, apareixen habitualment i els infants tot just han acabat o estan finalitzant el seu procés de desenvolupament fonològic.

Tenint això en compte, i havent treballat la mostra de paraules en la diversitat exposada, es va tornar a comprovar quins eren els processos de simplificació que havien intervingut en aquest nivell.

Les quantitats obtingudes venen a indicar que no van tenir quantitats destacables i que, del conjunt de processos, únicament les omissions de sons codals destaquen de la resta en un 10,4\% (infants), 7,9\% (mestres)

\section{TAULA PERCENTUAL DELS RESULTATS GLOBALS DEL NOMBRE DE PROCESSOS DE SIMPLIFICACIÓ FONOLÒGICA (TEXTOS 1, 2, 3).}

\begin{tabular}{|c|c|c|c|c|c|c|c|c|c|c|c|c|}
\hline \multicolumn{13}{|c|}{ NIVELL de SÍL·LABA } \\
\hline & \multicolumn{3}{|c|}{ Reduccions } & \multicolumn{3}{|c|}{ Omissions } & \multicolumn{3}{|c|}{ Epèntesi } & \multicolumn{2}{|c|}{$\begin{array}{c}\text { Coalescènci } \\
\text { a }\end{array}$} & $\begin{array}{c}\text { Metà } \\
\text { tesi }\end{array}$ \\
\hline $\begin{array}{c}\text { infan } \\
\text { ts }\end{array}$ & 4,92 & 3,9 & 3,7 & 8,4 & 10 & 5,7 & 0 & 1 & 2,5 & 0,59 & $\begin{array}{c}1,1 \\
8\end{array}$ & 0,39 \\
\hline $\begin{array}{c}\text { mest } \\
\text { res }\end{array}$ & 9,27 & 1,3 & 2,6 & 3,3 & 7,9 & 0 & 0 & 1,3 & 1,9 & 0 & 0 & 0,66 \\
\hline
\end{tabular}

Coeficient de correlació $=0,70$

Taula 9. Resultats i anàlisi estadística dels procesos de simplificació fonológica. Nivell de síl·laba.

Per altra banda, no totes aquestes omissions corresponen a sons inclosos en els perfils fonològics, dissenyats per edats i nivells. Segons això, són processos que haurien d'estar superats per infants d'aquestes edats. Certament, s'han classificat sons com $[K]$, [r] [1], que són d'incorporació més tardana, que podrien fer pensar en processos de desenvolupament fonològic alentits, però al davant d'aquests també s'han classificat [m], [b], [k], etc. que no es podrien considerar de la mateixa manera.

Quant a nivell segmental, dins dels processos per substitució, el coeficient de correlació és altíssim: 0,98\%, tenint en compte que el nivell màxim és 1 i que tot i que no és total, permet qualificar-lo de molt elevat.

TAULA PERCENTUAL DELS RESULTATS GLOBALS DEL NOMBRE DE PROCESSOS DE SIMPLIFICACIÓ FONOLÒGICA (TEXTOS 1, 2, 3).

\begin{tabular}{|l|c|c|c|c|}
\hline \multicolumn{1}{|l|}{ NIVELL SEGMENTAL } \\
\hline Infants & $\begin{array}{c}\text { Mode } \\
\text { d'articulació }\end{array}$ & $\begin{array}{c}\text { Lloc } \\
\text { d'articulació }\end{array}$ & Sonorització & insonorització \\
\hline mestres & 22,83 & 6,88 & 7,28 & 4,72 \\
\hline
\end{tabular}

Coeficient de correlació: 0,98

Taula 10. Resultats i anàlisi estadística dels procesos de simplificació fonológica. Nivell segmental. 
El mode d'articulació és el que va presentar uns valors més alts que els altres. La semiconsonantització del so $[K]$ és el que va tenir una presència més destacada. Es van arribar a comptabilitzar, en total, 32 per part dels infants i 44 per part de les mestres. La correlació va ser un fet evident.

El lloc d'articulació no va presentar dades massa significatives, segons es pot comprovar a l'anàlisi estadística.

La sonorització de les oclusives i algunes fricatives sordes van tenir la seva atenuada presència en algunes produccions de tots els informants.

En resum, aquesta correlació infants-mestres verifica la hipòtesi de partida, en el sentit que quan els infants van interactuar amb les seves mestres van produir la parla segons el model que havien sentit. I que, efectivament, aquests processos de simplificació fonològica, tal com s'ha anat exposant, van tenir el seu origen en les característiques pròpies de la parla espontània o semiespontània. Això sense oblidar que aquests infants van tenir únicament com a interlocutores en llengua catalana les seves mestres i mai no havien estat alfabetitzats.

\section{CONCLUSIONS}

El nucli de la recerca era trobar les causes de les desviacions en la parla dels infants de 2-3 anys, amb capacitats adequades, quan interactuen amb l'adult en la conversa semiespontània.

Les conclusions han derivat de la traçabilitat de les dades estudiades i de la mostra de 617 paraules analitzades.

Tota vegada que el propòsit era conèixer els factors que intervenien en la parla espontània, quan els infants no reproduïen amb fidelitat el model adult en la llengua que sentien, les conclusions van respondre a factors fonològics i prosòdics.

Els fonològics es refereixen al procés de desenvolupament fonològic, a l'adquisició de sons, als trets distintius, etc. Així, a partir de la investigació:

- Es va constatar que els infants van demostrar una excel·lent discriminació fonològica.

- Es va comprovar que no transgredien la seva consciència fonològica estrictament quan canviaven sons, sinó que s'hi acomodaven.

- Es va verificar una percepció correcta del nombre de síl-labes. Si en alguns casos no havien estat reproduïdes amb els sons idèntics als de la mestra, sí les havien verbalitzades d'alguna manera. Ex:

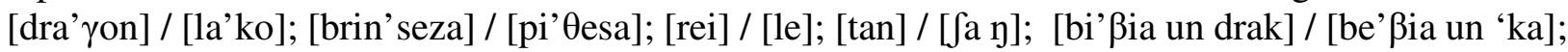
[fok] / [Xo]; [unes'kut] / [ulas'ku], etc.

Els factors prosòdics comprovables en el terreny de la parla espontània i no únicament en el del laboratori de fonètica, tenen a veure amb la fluïdesa, els gestos articulatoris, la rellevància psicoacústica natural que envolta la producció de sons, l'adquisició de la pronunciació i la presència de la competència comunicativa com element innovador dins d'aquesta variable prosòdica (lingüística, discursiva, cultural, estratègica...).

- Es va constatar que hi havia altres fenòmens de tipus prosòdic, complementaris als processos de simplificació fonològica, que van permetre donar una mirada més ajustada a l'anàlisi de la producció i la percepció de la parla espontània, com la competència comunicativa.

- Es va confirmar que més enllà del sistema fonològic, l'emissió dels sons també ve determinada per un conjunt de factors, entre els que hi ha la percepció, la producció, la mediació i la interacció en el marc de la parla espontània, que precisen d'una sèrie de recursos que la competència comunicativa 
regula: l'entonació de la paraula, el timbre, l'èmfasi, l'allargament de sons, la varietat dialectal, la càrrega emocional, el sentiment d'empatia envers la mestra, el relat, etc. A més a més, cal tenir en compte el significat, que l'infant ha d'identificar i ha de pronunciar de manera fonològicament correcta.

- També es va comprovar que l'infant té la capacitat d'imitar, modificar i d'incloure també la fluïdesa, la interacció dels gestos articulatoris, és a dir, tota la percepció subjectiva de les característiques del so i de l'expressió oral.

- Al quadre 3 es presenten els elements que s'ha comprovat que intervenen en la percepció de la parla, amb inclusió d'uns indicadors de graus de coincidència. Igualment, es va constatar que en funció del grau de coincidència amb el model rebut, cada infant va manifestar quin tipus de competència comunicativa tenia aparellada en relació als fenòmens prosòdics que havia d'implementar en les seves produccions.

Aquestes conclusions relacionades amb el primer objectiu van presentar una visió més globalitzadora al reunir les variables del camp fonològic i del prosòdic, sobretot a l'incorporar la competència comunicativa dins dels components prosòdics com a element innovador.

Quant a la comprovació de la interrelació entre el procés de desenvolupament fonològic i els perfils fonològics existents, elaborats per edats i nivells, les conclusions van ser les següents:

- Es va comprovar que no sempre hi va haver una interrelació entre els processos de simplificació fonològica i els perfils i nivells per edats que habitualment es donen com a estàndard tradicional.

- Habitualment, es consideren grups consonàntics de realització difícil per a infants de 4 anys: [gr], [fl], [pr], [bl]. No obstant això, en la mostra de paraules els informants de 2 a 3 anys, van pronunciar correctament aquests sons en paraules com [grok], [sa'grada], [flo], [prin'seza], ['plora], [blaw]. Fins i tot en diftongs decreixents com [au] / [gau'di]; [ei] / [rei].

- Es va comprovar que en les dades recollides a les anàlisis de la mostra de paraules, existien fenòmens que no havien entrat sempre en els perfils globals per edats i nivells.

- De fet, els perfils tipificats existents s'orienten cap a la intervenció i reeducació i, a la vegada, per a infants amb les capacitats lingüístiques, comunicatives i cognitives adequades i, com s'ha comprovat en el cas d'aquests últims no sempre les seves simplificacions fonològiques van respondre als perfils estandarditzats. Exemples:

- Semiconsonantització del so [ $\lambda]$, que la mestra va realitzar 9 de les 12 vegades que va sortir, els infants de 2-3 anys van imitar-lo 6 vegades.

- So oclusiu [k] en posició final al segment en les paraules [fok] i [drak]. Les mestres van sonoritzarlo a $[\mathrm{g}] 2$ vegades, el van ometre 2 , el van pronunciar bé 13 vegades.

- Al seu torn els infants el van assimilar a un so fricatiu [z] 1 vegada, el van ometre 5 vegades i el van pronunciar bé 11 vegades.

- Així mateix es va concloure que les incidències fonètiques no es podien considerar errades, sinó que calia veure-les dins de les característiques de la parla espontània, que va ser la situació comunicativa que es va utilitzar. Així, no seria correcte afirmar que els "errors" haguessin tingut sempre i només l'origen en els processos de simplificació fonològica relacionats amb el desenvolupament fonològic. 


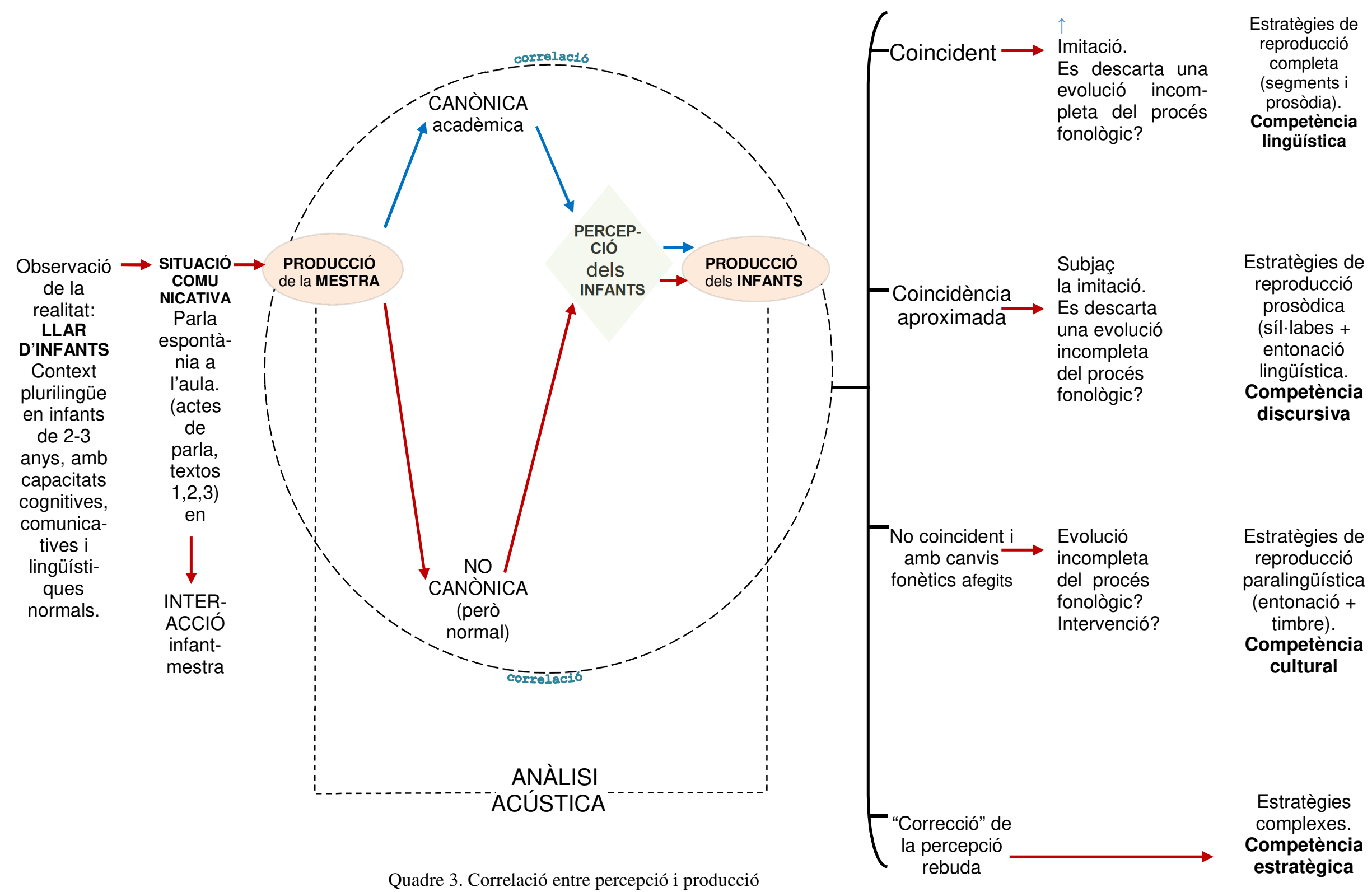


Quant a l'aspecte de constatar l'existència d'una correlació entre la percepció i la producció de la parla dels infants de 2-3 anys, les conclusions van ser les següents:

\section{Pel que fa als graus de coincidència:}

A partir de les dades de les taules quant a la producció fonològica (i prosòdica) de cada infant d'acord amb els graus de coincidència establerts i segons el model rebut de la mestra, es va constatar que hi va haver un elevat percentatge de coincidències en el resultat de l'anàlisi de la correlació entre percepció i producció, ja que els infants acostumaven a reproduir el model de la mestra, segons mostren les correlacions estudiades, extensives a la percepció i producció.

\section{Pel que fa als processos de simplificació fonològica:}

Es va constatar que les produccions de les mestres en interacció amb els infants incloïen en el seu model elisions, assimilacions, epèntesis... Donat que es tracta de fenòmens propis dels infants de 2-3 anys i les mestres han sobrepassat òbviament aquesta edat, no es pot dir que elles estiguessin realitzant processos de simplificació fonològica a causa de no tenir el seu desenvolupament fonològic acabat. Cal pensar que si les seves produccions han estat similars a les dels infants és perquè van manifestar les característiques diferenciadores de pronúncia habituals en la parla espontània que els infants van imitar.

També es va comprovar que el resultat de les anàlisis estadístiques a nivell de sil·laba la correlació va ser alta: 0,70; a nivell de segment, encara va resultar ser més alta: 0,98, quan l'índex màxim de correlació és 1 .

En conclusió, el punt de partida sobre si la desviació en la percepció de la parla per part dels infants obeeix al desconeixement de la llengua escrita i a les característiques de la parla espontània, va aconseguir una generosa verificació, perquè els percentatges i els valors de les anàlisis estadístiques van permetre afirmar que els infants de 2-3 anys aproximadament, quan interactuen amb l'adult, fan una formidable acomodació de recursos. Aquesta acomodació no es pot associar només al seu desenvolupament fonològic sinó a les característiques diferenciadores de la parla espontània que, més endavant, quan facin la descoberta de la llengua escrita, segurament transformaran en produccions fonològicament correctes.

D'aquí que sigui important tenir en compte la inclusió dels factors prosòdics en l'anàlisi de la percepció i la producció de la parla que sovint queden bandejats o molt distants a l'hora d'investigar els actes de parla dels infants. D'igual manera, seria adient implementar la importància de la precisió verbal i lingüística en el grau de mestres de llars d'infants d'aquesta edat, atès que hi ha paraules específiques que necessiten d'una pronúncia més ponderada, que en la conversa semiespontània no sempre és evident. 


\section{REFERÈNCIES BIBLIOGRÀFIQUES}

Aceña, José M. (1996): Adquisición y desarrollo del nivel fonológico: intervención didáctica en retrasos y trastornos fonológicos y fonéticos. Madrid. Didáctica 8, 11-27. Servicio de Publicaciones UCM.

Aguilar, E. M., Serra, M (2004): A-RE-PA Anàlisi del retard de la parla. Publicacions Universitat de Barcelona.

Bartolí, M. (2014): La pronunciación por tareas en la clase de ELE. Phonica, vol. 9-10.

Bosch, Laura (1983b): Identificación de procesos fonológicos de simplificación en el habla infantil. Revista de Logopedia y Fonoaudiología, I.

Bruner, J. (1983 i 1985): La parla dels infants. Com s'aprèn a fer servir el llenguatge. Vic: Eumo Editorial.

Vers.cast. (1986): El habla del niño. Barcelona: Paidós

Cantero, F. J. (2015): De la fonética del habla espontánea a la fonología de la complejidad. Normas (Revista de Estudios Lingüísticos Hispánicos), núm.5.

Chomsky, N. (1975): Reflections on language. New York: Random House.

Clark, H.H. i Clark, E.V. (1977): Psychology and Language. New York: Harcourt Brace Jovanovich.

Dale, P. S. (1980): Desarrollo del lenguaje: un enfoque psicolingüístico. México. Trillas.

Ferguson, Ch. i Garnica, O. (1982): Teorías del desarrollo fonológico. Dins E. Lenneberg i E. Lenneberg (Comps.). Fundamentos del Desarrollo del Lenguaje. Madrid. Alianza Universidad Textos.

Fry, D.B. (1982): Aspectos fonológicos de la adquisición del lenguaje en la audición y la sordera Dins E. Lenneberg i E. Lenneberg (Comps.). Fundamentos del Desarrollo del Lenguaje. Madrid. Alianza Universidad Textos.

Giralt, M. (2006): El enfoque oral en la enseñanza del español como lengua extranjera: experiencia piloto de una propuesta didáctica. Phonica. vol 2.

Goldsmith, J. (1990): Autosegmental and metrical phonology. Nueva York: Garland Press.

González, M.J. (1989b): Análisis del desarrollo fonológico en sujetos malagueños. Dins Infancia y Aprendizaje, 48.

Grunwell, P. (1985): Phonological assessment of child speech (PACS). Windsor: NFER-Nelson.

Hodson, B.W. i Paden, E.P. (1981): Phonological process which characterize unintelligible and intelligible speech in early childhood. Journal of Speech and Hearing Disorders, 46.

Ingram, D. (1974): Phonological rules in young children. Journal of child language, 1.

Jakobson, R. (1941): Kindersprache, Aphasie and Allgemeine Lautgesetze.Upsala, s.e. (versió espanyola), 1974. Madrid. Ayuso.

Kenstowicz, M. (1994): Phonology in generative grammar. Cambridge: Blackwell.

Mowrer, O.H. (1960b): Learning Theory and the symbolic processes. New York, Wiley.

Nadeu, C. (2012): Les tecnologies de la parla. A: G. Colom i L. Gimeno (eds). La lingüística i les seves aplicacions en la societat. Barcelona: Publicacions de la Universitat Jaume I. 
Peperkamp, S. (2003): Phonological acquisition: Recent attainments and new challenges. Language and Speech, 46, 2/3.

Prince, A. i Smolensky, P. (1993): Optimality theory: constraint interaction in generative grammar. Technical Report \#2 of the Rutgers Centre for Cognitive Science, Rutgers University.

Serra, M. (1979): Normas estadísticas de articulación para la población escolar de 3 a 7 años en el área metropolitana de Barcelona. Dins VI Congreso Nacional de Psicología. Pamplona.

Shvachkin, N.K. (1973): The development of phonemic speech perception in early childhood. A. Fergusson, C. i Slobin, D.: Studies of child language development. Holt, Rinehart and Winston. New York.

Spalacci, M., (2014): Enfoque oral digital para el aula de francés LE, con fines profesionales. Phonica, vol $9-10$.

Stampe, D. (1969): The acquisition of phonetic representation. Dins Papers from the Fifth Regional Meeting of the Chicago Linguistic Society, Chicago. Chicago Linguistic Society.

Vihman, M.M., (2014). Phonological Development. The first two years. Wiley Blackwell

Vila, I. (1999): Jerome Bruner i l’adquisició del llenguatge. Barcelona: Temps d'Educació, 21.

Vila, I. i al. (2001): Processos psicològics bàsics. Barcelona: Edicions de la Universitat Oberta de Catalunya (EDIUOC). Col. Manuals, 40.

Waterson, N. (1971): Child phonology: a prosodic view. Journal of Linguistics, 7. 